\title{
MODELLING OF HEAT RECOVERY FROM SUSPENDED OIL
}

\author{
WELLS \\ By \\ Steven James England \\ Bachelor of Engineering (B.Eng.) \\ Ryerson University, Toronto, 2015

\begin{abstract}
A MRP
presented to Ryerson University
\end{abstract} \\ in partial fulfillment of the \\ requirements for the degree of \\ Master of Engineering \\ in the Program of \\ Mechanical and Industrial Engineering
}

Toronto, Ontario, Canada, 2017

(C) Steven James England 2017 


\section{AUTHOR'S DECLARATION}

I hereby declare that I am the sole author of this thesis. This is a true copy of the thesis, including any required final revisions.

I authorize Ryerson University to lend this thesis to other institutions or individuals for the purpose of scholarly research.

I further authorize Ryerson University to reproduce this thesis by photocopying or by other means, in total or in part, at the request of other institutions or individuals for the purpose of scholarly research.

I understand that my thesis may be made electronically available to the public. 


\title{
ABSTRACT
}

\author{
Modelling of Heat Recovery from Suspended Oil and Gas Wells \\ Steven James England \\ Master of Engineering 2017 \\ Mechanical and Industrial Engineering \\ Ryerson University, Toronto
}

A geothermal system for suspended oil wells is designed to produce $1.25 \mathrm{MW}$ of heat. After a review of literature, a concentric double pipe heat exchanger was the system chosen. A control volume model was created to calculate the heat transfer characteristics of the system. After completing the model a suspended oil well near Hinton, Alberta was selected as a candidate well for a geothermal system. The well contains 33 perforated sections which need to be closed off. Three designs to accomplish this are proposed. The model predicted that the best design uses cement squeezes to close off the perforations and produces a net energy of $2.4 \mathrm{MW}$ at its optimum operating condition, with a mass flow rate of $8.18 \mathrm{~kg} / \mathrm{s}$. When producing $1.25 \mathrm{MW}$ of heat, the design has a net energy of $1.2 \mathrm{MW}$. It is found that internal heat generation plays a large roll in these systems. 


\section{ACKNOWLEDGEMENTS}

I would like to thank Dr. Naylor for supervising my master's project. His passion for engineering was evident at each of our meetings, and was a constant source of motivation and inspiration while completing this project. I could not have completed this without his support.

To T.M. Gunderson for his support and encouragement throughout my master's degree. Thank you for providing valuable resources for the completion of this project. I look forward to working with you in the future.

To Jenny Mason for her unwavering love and support, I would not be where I am today without you.

And finally, to my friends and family, I am grateful for all the words of encouragement and support throughout this process. 


\section{Table of Contents}

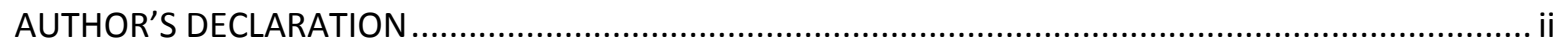

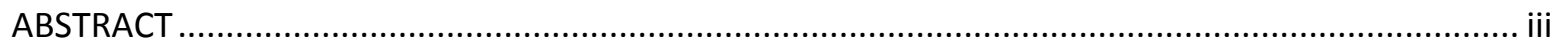

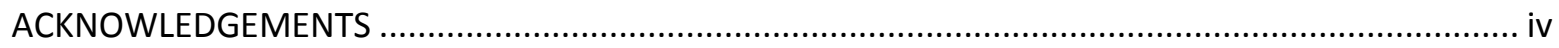

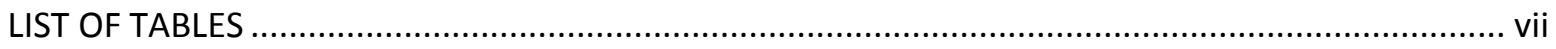

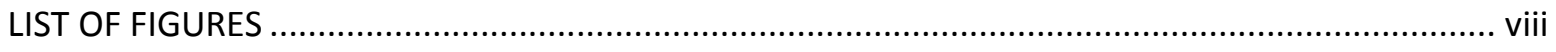

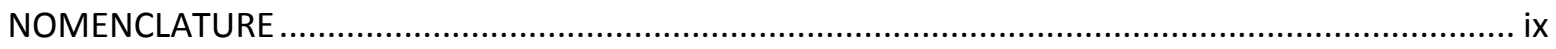

Chapter 1 Introduction and Literature Review ........................................................................... 1

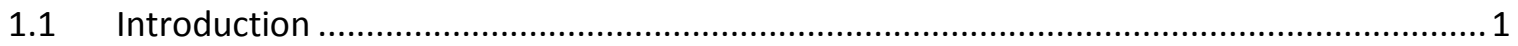

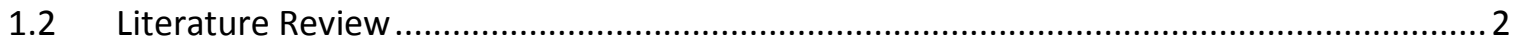

1.2.1 Geothermal Energy Systems Overview................................................................ 2

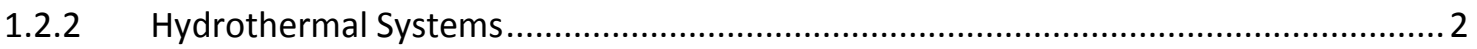

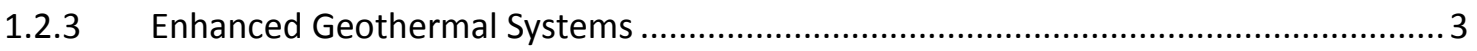

1.2.4 Concentric Double Pipe heat Exchangers in oil and gas wells .................................. 7

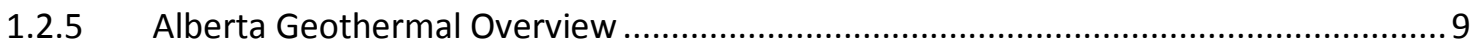

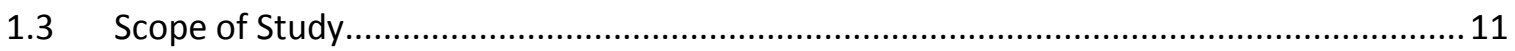

Chapter 2 Problem Description and Modeling Procedure ........................................................... 12

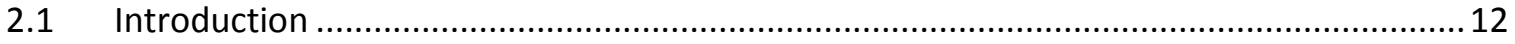

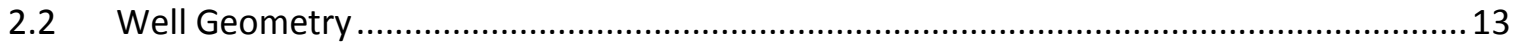

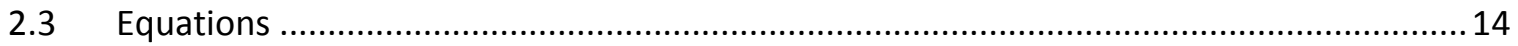

2.3.1 Concentric Tube Heat Exchanger Feasibility Test ................................................... 14 


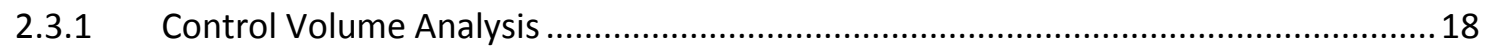

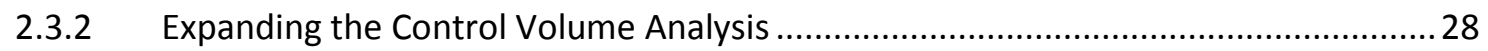

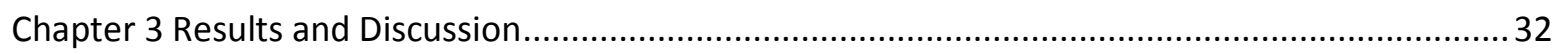

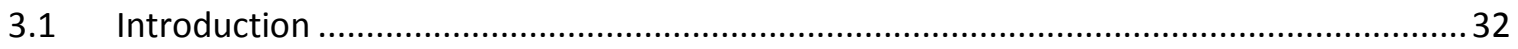

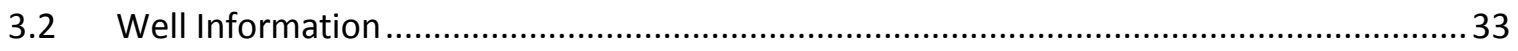

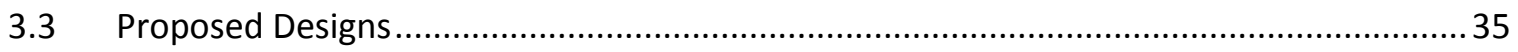

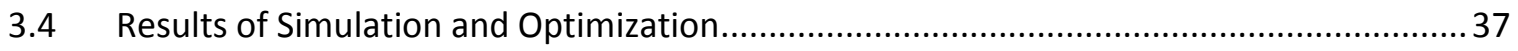

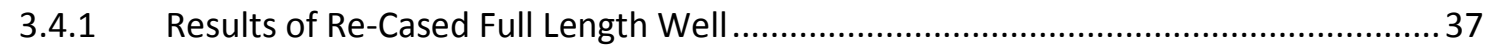

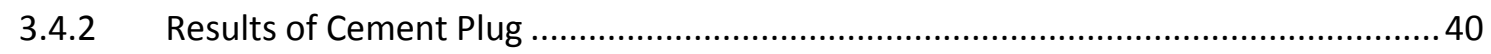

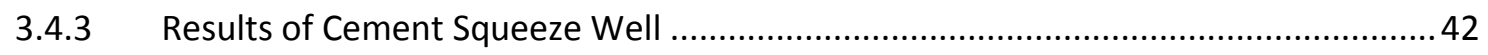

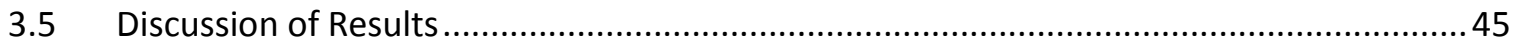

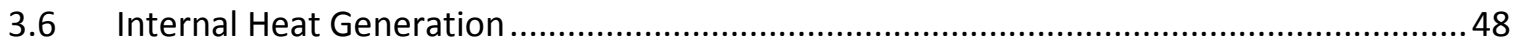

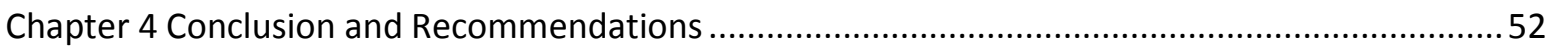

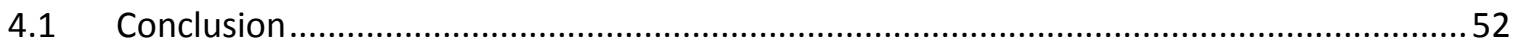

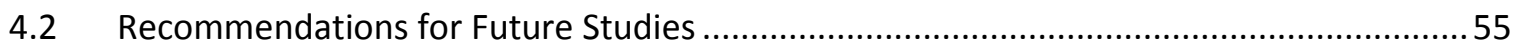

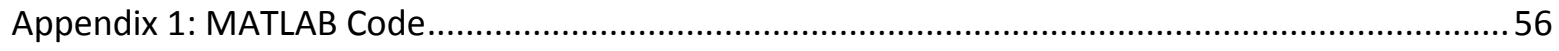

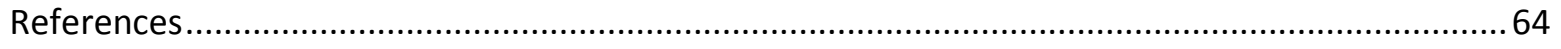




\section{LIST OF TABLES}

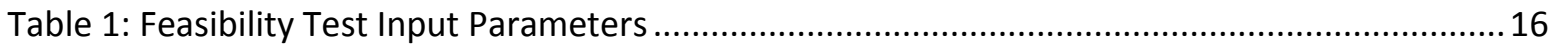

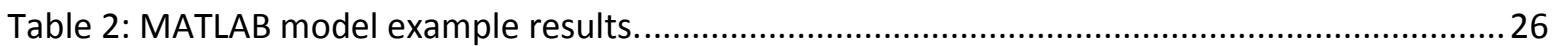

Table 3: Casing Program used for MATLAB model including well casing thermal resistor example

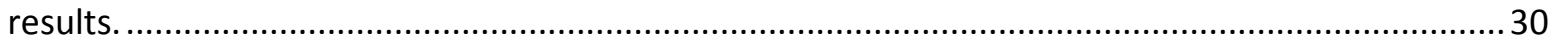

Table 4: MATLAB model including well casing thermal resistor results. ........................................30

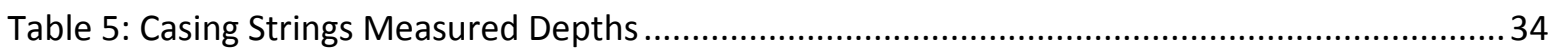

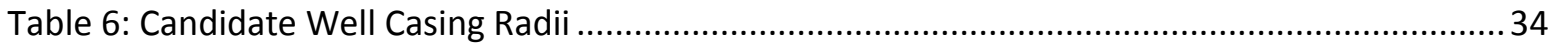

Table 7: Formation Temperature Gradient Information............................................................... 35

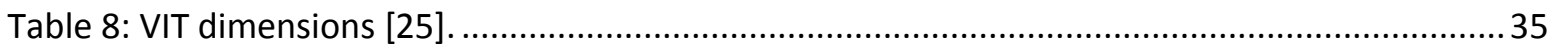

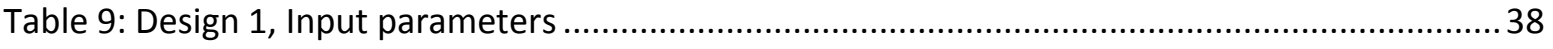

Table 10: Design 1, Optimized Design Results .............................................................................. 39

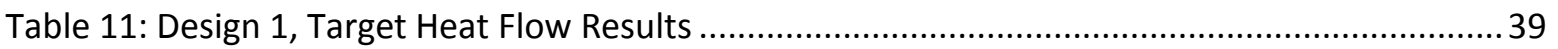

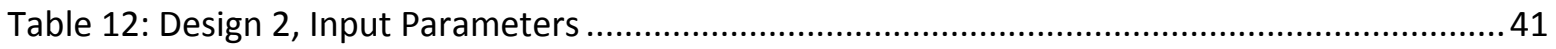

Table 13: Design 2, Optimized Design Results ............................................................................ 42

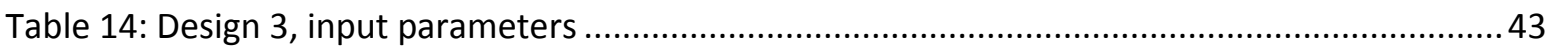

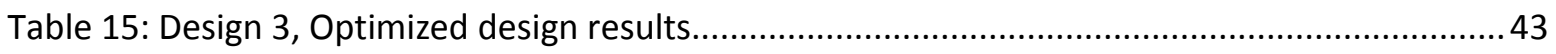

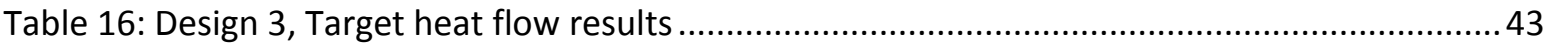

Table 17: Comparison of Optimized Well Configurations ............................................................ 45

Table 18: Comparison of 1.25MW Heat Output Configurations.................................................. 45

Table 19: Design 1, Effect of Internal Generation on 1.25MW Heat Flow Regime ............................50 


\section{LIST OF FIGURES}

Figure 1: U-tube Designs tested by Steins et al. [10] (a) without a promotor pipe, (b) with a US designed promotor pipe, (c) with a New Zealand designed promotor pipe, (d) with air lift.............. 6

Figure 2: Average temperature at 3.5km below surface [21] .................................................... 10

Figure 3: Feasibility test comparing heat loss from return fluid to annulus fluid between vacuum

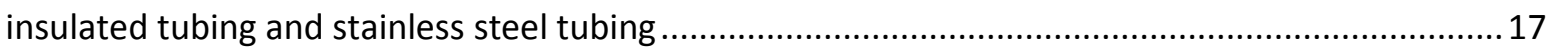

Figure 4: Well Diagram, Ignoring Casing Geometry .............................................................. 19

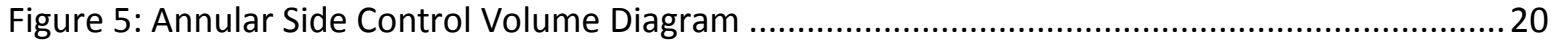

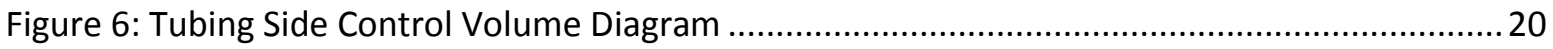

Figure 7: Fluid temperature profile of the MATLAB model example results................................ 27

Figure 8: Fluid temperature profile of the MATLAB model example at bottom hole...................... 27

Figure 9: Well Diagram Including Casing Geometry (left side only) ...............................................29

Figure 10: Fluid temperature profile of the MATLAB model including well casing thermal resistor

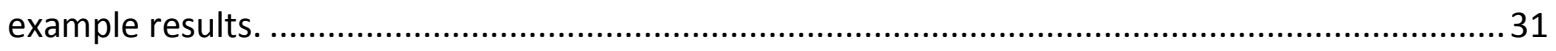

Figure 11: Design 1, Optimized Heat Flow Well Temperature Profile .............................................. 39

Figure 12: Design 1, Objective heat flow Temperature Profile .................................................... 40

Figure 13: Design 2, Exit Temperature versus Mass Flow Rate.................................................... 41

Figure 14: Design 2, Optimized Well Temperature Profile …........................................................ 42

Figure 15: Design 3, Optimized Well Temperature Profile ........................................................ 44

Figure 16: Design 3, Objective Heat Flow Temperature Profile. VIT Model 4.5X3.5 ...................... 44

Figure 17: Heat Flow Rate and Pumping Power of Design 2 with respect to the Mass Flow Rate.... 47

Figure 18: Design 1, Temperature Profile when Internal Heat Generation is Included ....................51 


\begin{tabular}{|c|c|}
\hline$A_{\text {annulus }}$ & Cross sectional area of annulus \\
\hline$A_{\text {tubing }}$ & Cross sectional area of tubing \\
\hline$A_{c}$ & Surface area of inside casing wall \\
\hline$A_{t}$ & Surface area of outside tubing wall \\
\hline$C_{p c}$ & Specific heat of the cold annular fluid \\
\hline$C_{p h}$ & Specific heat of the hot fluid within the tubing \\
\hline$d$ & Well depth \\
\hline$D$ & Diameter \\
\hline$D_{\text {eff }}$ & Effective hydraulic diameter \\
\hline$D_{h}$ & Hydraulic diameter \\
\hline$\epsilon$ & Wall roughness \\
\hline$f$ & Darcy-Weisbach frictional factor \\
\hline$g$ & Gravitational acceleration \\
\hline$h_{c}$ & Heat transfer coefficient of cold annular fluid \\
\hline$h_{h}$ & Heat transfer coefficient of hot fluid within the tubing \\
\hline$h_{\text {fannulus }}$ & Head loss caused by friction within the annulus \\
\hline$h_{\text {ftubing }}$ & Head loss caused by friction within the tubing \\
\hline$j$ & Control volume number \\
\hline$k_{\text {concrete }}$ & Thermal conductivity of concrete \\
\hline$k_{S S}$ & Thermal conductivity of stainless steel \\
\hline$k_{\text {steel }}$ & Thermal conductivity of casing steel \\
\hline$k_{t}$ & Thermal conductivity of vacuum insulated tubing \\
\hline$\dot{\boldsymbol{m}}$ & Mass flow rate \\
\hline$\mu$ & Dynamic viscosity \\
\hline$n$ & Total number of control volumes \\
\hline $\mathrm{Nu}$ & Nusselt number \\
\hline$P$ & Pressure \\
\hline$\rho_{c}$ & Density of cold annular fluid \\
\hline$\rho_{h}$ & Density of hot fluid within the tubing \\
\hline$P_{\text {pump }}$ & Pumping power required to overcome frictional losses \\
\hline $\operatorname{Pr}$ & Prandtl number \\
\hline$Q_{\text {formation }}$ & Heat flow from the formation into the annular fluid \\
\hline$Q_{\text {friction }}$ & Heat flow created by frictional losses \\
\hline$Q_{\text {in }}$ & Heat flow from previous control volume \\
\hline$Q_{\text {out }}$ & Heat flow into next control volume \\
\hline$Q_{\text {total }}$ & Total heat flow from system \\
\hline$Q_{\text {tubing }}$ & Heat flow between cold annular fluid and hot fluid within the tubing \\
\hline$R_{1}$ & Inside radius of the tubing \\
\hline$R_{2}$ & Outside radius of the tubing \\
\hline$R_{3}$ & Inside radius of the casing \\
\hline$R_{4}-R_{11}$ & Radii of casing strings \\
\hline
\end{tabular}




$\begin{array}{ll}R e & \text { Reynolds Number } \\ T & \text { Temperature } \\ T_{c} & \text { Temperature of cold annular fluid } \\ T_{h} & \text { Temperature of hot fluid within the tubing } \\ T_{r} & \text { Formation temperature } \\ T_{s} & \text { Surface Temperature } \\ u_{c} & \text { Thermal transmittance through casing } \\ u_{t} & \text { Thermal transmittance through tubing } \\ V_{\text {avg }} & \text { Average velocity } \\ V_{\text {annulus }} & \text { Average velocity of fluid within the annulus } \\ V_{\text {tubing }} & \text { Average velocity within the tubing } \\ \Delta X & \text { Length of control volume } \\ \zeta & \text { Reynolds number correctional factor for frictional losses }\end{array}$




\section{Chapter 1 Introduction and Literature Review}

\subsection{Introduction}

With the implementation of a Carbon Tax in the province of Alberta starting in 2017, as well as the phasing out of coal power by 2030 , there is a new demand for clean reliable energy for both heating and electricity [1] [2]. Geothermal technology has a great potential to help fill this gap in clean energy supply. The motivation for this project stems from the large excess of suspended gas wells present in Alberta that are being critically underused for their working capacity. A well is considered suspended when it has been inactive for either six or twelve months, depending on the type of well [3]. These wells can be repurposed to provide district heating for residential and industrial use, as well as the possibility of small-scale power generation. This study has set out to meet the need for industry to be able to assess wells for their potential based on the well geometry and formation temperatures, as well as aid in optimizing the retrofit design in order to maximize the net energy produced.

A Calgary based energy company has requested that a geothermal system be designed for application in suspended oil and gas wells in Alberta. The initial system is to be designed for a well with a total vertical depth of $3000 \mathrm{~m}$, a bottom hole temperature of $125^{\circ} \mathrm{C}$, and an internal casing diameter of $7^{\prime \prime}(0.1778 \mathrm{~m})$. A power output of $1.25 \mathrm{MW}$ of heat is to be provided by the system for municipal district heating. The design should consider the possibility that the well may be dry i.e. contain no hot geothermal fluids. Information on an actual well has been provided after the initial test system was designed. In order for the design to take place, a modeling program is needed to predict fluid flows and output temperatures within the well. 


\subsection{Literature Review}

\subsubsection{Geothermal Energy Systems Overview}

Geothermal energy is the heat energy found in the earth's crust left over from the formation of the planet and the decay of radioactive materials [4]. The earliest use of geothermal energy is the exploitation of hot springs found worldwide. These springs have been used for heating, bathing, and cooking for millenniums [5]. The first use of geothermal heat to produce electrical power began in 1904 in Larderello, Italy by utilizing the steam from a hot spring [5].

Geothermal resources can be divided into three categories based on the formation's temperature. High temperature formations have a temperature greater than $150^{\circ} \mathrm{C}$, and at these temperatures electricity production is economical. Intermediate temperature formations range from $90^{\circ} \mathrm{C}$ to $150^{\circ} \mathrm{C}$, and these formations are suitable for district heating and electricity production, although producing electricity at these temperatures becomes a less economic option and may require the use of a binary power plant. Low temperature formations are below $90^{\circ} \mathrm{C}$, and these formations are best suited to use in heat pumps and district heating, although power production with a binary power plant is still possible at temperatures as low as $74{ }^{\circ} \mathrm{C}$ [6] [7]. Geothermal energy systems themselves can be subdivided into two categories, Hydrothermal Systems, and Enhanced Geothermal Systems, both of which are useful for all grades of geothermal resource.

\subsubsection{Hydrothermal Systems}

Hydrothermal Systems utilize aquifers of hot water, extracting the hot fluid to surface where the fluids heat energy can be converted to electricity, or distributed as district heating [8]. These systems require the drilling of a well into the aquifer to allow for the geothermal fluid to be pumped to surface. Typically, geothermal energy is extracted from near surface hot spots. These hot spots are often located in areas of volcanic activity where the extracted fluids are found near surface, and at suitable 
temperatures for use in a steam power plant [4]. In the past, the geothermal effluent was disposed of into lakes, rivers, and irrigation systems but, the chemical compositions of geothermal effluents tend to make them unsuitable for surface disposal [7]. It is now common practice for new hydrothermal geothermal systems to be designed with an injection well to return the fluid back to the aquifer. This technique reduces the environmental impact of the geothermal power plant, by eliminating polluting effluent, as well as ensuring long term resource reliability by recharging the aquifer [7]. Hydrothermal systems are costly to put into production because multiple wells are needed to be drilled. The cost associated with implementing these wells can run upwards of 40 percent of the total cost of the geothermal power plant [9].

\subsubsection{Enhanced Geothermal Systems}

Enhanced geothermal systems are used to extract heat energy from hot dry rock formations, or depleted hydrothermal wells. Enhanced geothermal is generally the injection of a fluid, through an injection well, into a porous hot rock formation. The water travels through the formation, where it collects heat, and is extracted through the production well back to surface [8]. In situations where hot dry rock is present, but there is not the necessary permeability in the formation, hydraulic fracturing can be used to create a network of cracks in the formation to connect the production and injection wells [8].

Down hole heat exchangers (DHE) fall in the category of enhanced geothermal systems and are a way of utilizing geothermal resources without the need to produce geothermal fluids to surface [10]. They are used in situations where producing geothermal fluids to surface is undesirable or not permitted. For example, in Rotorua New Zealand where over extraction of the geothermal aquifer caused the Papakura geysers to stop flowing [10]. This prompted drastic change to the geothermal policies in the area, including mandatory full reinjection of produced fluids. Local council has also begun to encourage the use of down hole heat exchangers as a more efficient use of the geothermal resource 
[10]. The most common form of DHE for applications in geothermal aquifers is the U-Tube heat exchanger. For applications in hot dry rock formations where a closed system is desirable or formation permeability does not allow for fluid flow, concentric double pipe heat exchangers are the most common design choice.

The main drawback of DHE's compared to enhanced geothermal systems which produce fluids from the rock formation, is the restricted energy output [10]. DHE bore holes are required to accommodate two directions of fluid flow in either the form of a U-tube, or a concentric double pipe heat exchanger. This results in a lower max flow rate than in enhanced geothermal systems producing fluids from the formation. In addition to limited flow rates, DHE's only have, the internal surface area of the well bore to receive heat from the formation, compared to fluid pumped through a geothermal formation, where the entire fracture network is available to transfer heat to the geothermal fluid.

U-tube heat exchangers came into existence in 1931 when the first of its kind was installed in Klamath Falls, Oregon. This original system lasted 25 years, and has since been widely adopted in the area for use as a supply of domestic heating [11]. A basic U-Tube DHE consists of a down pipe, return pipe, and a $U$ shaped joint which smoothly changes the direction of flow back to the surface [10]. Acting as a shell and tube heat exchanger, heat is collected from naturally occurring geothermal fluid present in the well bore and returned to surface. The design common in Klamath Falls consists of a 100m deep, $254 \mathrm{~mm}$ diameter well cased with a $203 \mathrm{~mm}$ diameter steel pipe. The casing is perforated at the bottom, and just below the static water level. Two U-tube loops are installed, first a $50.8 \mathrm{~mm}$ diameter U-tube for heating purposes, followed by a $19.05 \mathrm{~mm}$ diameter U-tube for hot water [11]. Freestone and Pan expect that wells with a depth of $70-120 \mathrm{~m}$ deep and a bottom hole temperature of $90-100^{\circ} \mathrm{C}$ can produce a heat output of around 0.8MW [11]. Steins et al. [10] investigates methods of improving the heat transfer to the U-tube by creating convection currents within the well bore. 
Due to regulation changes and over extraction of a large geothermal aquifer in New Zealand, DHE systems have been encouraged in that region. Steins et al. [10] set out to investigate methods for improving the performance of U-tube DHE's in the region of Rotorua New Zealand, specifically at the Alpine Motel. The well used is 55 meters deep, with a casing inside diameter of $150 \mathrm{~mm}$ and a peak bottom hole temperature of $138.1^{\circ} \mathrm{C}[10]$. The method for increasing performance studied, was increasing the circulation within the well. This was conducted by three methods; a promotor pipe of American design, a promotor pipe of New Zealand design, and an airlift system.

The American designed promotor pipe works by placing the U-tube within a promotor pipe with perforations on either end. This creates a convection cell within the well, where hot water rises up the annulus, and the cooling water falls through the promotor pipe. The New Zealand design works in a similar manner, except the promoter pipe is located off to the side of the U-tube. It was found that with either of these promotor pipe designs, if optimally designed, the circulation induced is the same. The inclusion of a promotor pipe has shown to increase the heat output of a well by 60 percent -120 percent [10].

An airlift system is used to promote flow in the well by producing a small amount of fluid at surface ( $1.5 \mathrm{~L} / \mathrm{min})$. The system works by inserting a pipe a short distance below the well head. A small nylon tube is run to a depth of 1 meter from the end of the inserted pipe. Air is pumped through the nylon tube creating an air-water mixture in the pipe. Due to this mixtures lower density and the static pressure head, the mixture is forced to surface. The airlift system is able to promote flow from the aquifer into the well. By introducing new hot fluid into the well bore, a higher temperature is maintained within the well. The implementation of an airlift system by Steins et al. at the Alpine Motel in Rotorua New Zealand increased the heat output from 20 kW to 45kW, a 125 percent increase. 


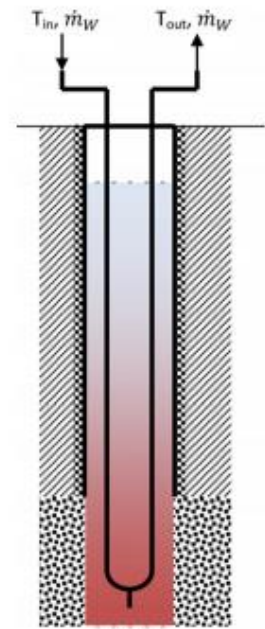

(a)

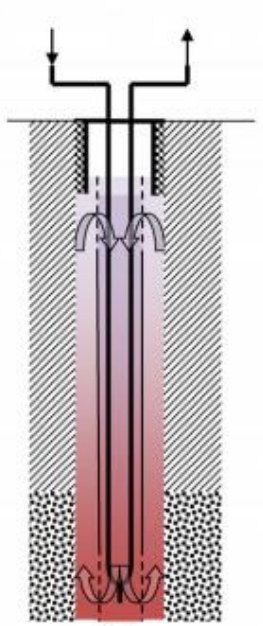

(b)

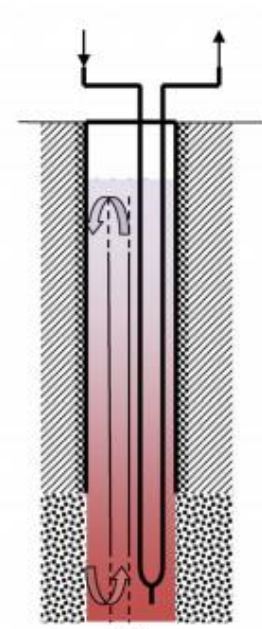

(c)

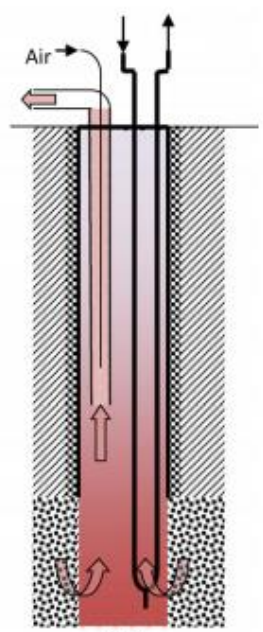

(d)

$\begin{array}{lll}\text { \& Cement } & \text { W/ Ground } \\ \text { to Feedzone } & \square & \text { Flow direction }\end{array}$

Figure 1: U-tube Designs tested by Steins et al. [10] (a) without a promotor pipe, (b) with a US designed promotor pipe, (c) with a New Zealand designed promotor pipe, (d) with air lift.

The concentric double pipe DHE's design allows the system to take advantage of the entirety of the borehole surface area for the conduction of heat into the working fluid. The system consists of the borehole casing, and an insulated tube in the center of the well extending from surface to a depth just above the bottom of the well. The borehole is required to be completely sealed to prevent the loss and contamination of the working fluid. In some cases, this may require a new string of casing to be inserted and cemented into the well which will lower the optimum flow rate. Another possible option would be installing a cement plug above the highest perforation limiting the usable depth both of which are costly to implement. The system works by sending the working fluid from surface down the annulus where the fluid collects heat through the casing from the rock formation. When the fluid reaches the bottom of the well and has achieved its maximum temperature, the fluid returns up the insulated tubing. The insulated tubing prevents heat loss to the cold fluid entering the system near surface. 
Noorollahi et al. [12] investigated the reworking of a geothermal well drilled in the Meshkinshahr geothermal field in the Sabalan district of northwest Iran. The abandoned well in question was drilled as part of the first Iranian geothermal power generation project. The well was drilled along with 11 other exploration wells into the geothermal field between 2002 and 2012, and was the only well to be nonproductive. It was discovered that the well was separated from the geothermal field by a sealing fault, and would not be suitable as a geothermal well or a reinjection well. Noorollahi et al. propose the dry well be repurposed as a concentric double-pipe heat exchanger to exchange heat, but not transfer mass between the system and formation. The well has been drilled to a depth of $3176 \mathrm{~m}$, the casing geometry consists of a $0.2445 \mathrm{~m}\left(9 \mathrm{5} / \mathrm{8}^{\prime \prime}\right)$ casing from surface to a depth of $1599 \mathrm{~m}$, a $0.1778 \mathrm{~m}\left(7^{\prime \prime}\right)$ liner is hung from to a depth of $2654 \mathrm{~m}$, followed by a $0.127 \mathrm{~m}\left(5^{\prime \prime}\right)$ liner hung to $3176 \mathrm{~m}$. The proposed design is an inserted steal pipe surrounded by bentonite clay inside the well and capped at the bottom. This pipe is followed by a second polystyrene insulated steal pipe hung inside to a length slightly shorter than the first pipe. Cold fluid is run down the annulus where it is heated by the rock formation, and then returned to surface through the center pipe. The study focused on finding the optimum mass flow rate for the system in order to maximize the exit fluid temperature, without investigating how to minimize the required pumping power. Through an Ansys simulation using a control volume finite difference method, an outlet temperature of $138.2^{\circ} \mathrm{C}$ at a mass flow rate of 6.03 $\mathrm{kg} / \mathrm{s}$ was predicted.

\subsubsection{Concentric Double Pipe heat Exchangers in oil and gas wells}

An investigation into the utilization of oil wells for electricity generation was conducted by Kharseh et al. [9]. The study investigated converting oil wells for use in a binary geothermal power generation system. The thermodynamics of the oil well were not simulated, and the outlet temperatures were assumed for two separate cases as $100^{\circ} \mathrm{C}$ and $120^{\circ} \mathrm{C}$ both at a flow rate of $1 \mathrm{~kg} / \mathrm{s}$ and 
a sink temperature of $29^{\circ} \mathrm{C}$. The investigation concluded that $\mathrm{R} 32$ is the optimal working fluid in the binary power plant, and that a payback period of less than six years is possible in Qatar.

Noorohalli et al. proposed a design for retrofitting wells for geothermal power where a new string of well casing surrounded by bentonite clay is inserted into the well, followed by an insulated center pipe creating a double pipe heat exchanger [13]. Wight and Bennett suggest that the working fluid in a closed well bore retrofitted for geothermal power production should be water, as opposed to organic fluids, to avoid the risks of contamination [14].

In a study by Noorohalli et al. [13] two wells were numerically simulated in southern Iran. The wells had bottom hole temperatures of $138.7^{\circ} \mathrm{C}$ and $159.8^{\circ} \mathrm{C}$, and depths of $3861 \mathrm{~m}$ and $4423 \mathrm{~m}$. A 3D technique within Ansys was used for the simulation, and actual well geometry and geological layers were considered. Wight and Bennett [14] employed a more generalized approach, using 2500 Texas wells to determine the average geothermal gradient and surface temperatures in the area. The study discounts changes in fluid density caused by temperature changes for the calculation of pumping power. Wight and Bennett concludes that with a thermal gradient of $0.311^{\circ} \mathrm{C} / \mathrm{m}$, flow rate of $2.5 \mathrm{~kg} / \mathrm{s}$, and a well bore depth of $4200 \mathrm{~m}, 109 \mathrm{~kW}$ can be generated.

A mathematical model was developed by Bu et al. [15] to solve for the heat exchange from the ground formations into the geothermal fluid. The model investigates how the temperature of the surrounding rock changes over time, a factor which many studies ignore including Davis and Michaelides [16], Kharseh et al. [9], Noorollahi et al. [13] [12], and Wight and Bennett [14]. The study concludes that after a ten-year period, the water temperature extracted from the well in question will only drop by $2^{\circ} \mathrm{C}$. As well, the radius from the well effected by energy extracted is found to be a $20 \mathrm{~m}$.

Templeton et al. [6] developed a reliable heat transfer model for a double pipe heat exchanger for retrofitted abandoned oil wells. The model was developed in FlexPDE using the Galerkin finite 
element method. The model utilized rock properties and well dimensions based on abandoned wells in the Persian Gulf. Templeton is critical of similar investigations into simulating an oil well retrofitted as a double pipe heat exchanger by Bu et al. [15], Davis and Michaelides [16], and Kujawa et al. [17] for their over use of the Dittus-Bolter relation to simplify the Nusselt number calculations. Templeton found that the model created by Davis and Michaelides [16] is the most accurate of the three, yet still overestimates the power produced by 25 percent for a low flow model, and produces an over estimation of 135 percent for a high flow model.

\subsubsection{Alberta Geothermal Overview}

On May 14,1914 at a depth of 828 meters $\left(2718^{\prime}\right)$ Dingman \#1, the first well drilled by the Calgary Petroleum Products Company, struck a reservoir full of naphtha in the Turner Valley area south of Calgary [18]. The strike caused a boom of drilling activity in the area, although it was short lived. No crude oil was found during this early development which dissuaded investors, this in combination with the outbreak of the first world war caused drilling to come to a standstill. In the 1920's drilling had a slight pick-up, but the industry really took off in 1936 near the end of the great depression when the Turner Valley Royalties no. 1, near Turner Valley, but outside of the Turner Valley naphtha pay zone, struck crude [18]. Since the crude strike in 1936 over 500,000 wells have been drilled in Alberta, fueling the Canadian economy and providing Alberta with a wealth far greater than could have been anticipated [19]. The wells currently listed as suspended are possible candidates for a geothermal retrofit system, reducing the number of wells down to 102565 [19]. A further factor which needs to be considered is the bottom hole temperature of these wells.

The geothermal gradient in Alberta varies greatly over the province. Temperature gradients are found as low as $10^{\circ} \mathrm{C} / \mathrm{km}$ to as high as $55^{\circ} \mathrm{C} / \mathrm{km}$. Three hot spots have been identified in Alberta, the Skeen river area of northwest Alberta, the area around Fort McMurray in north eastern Alberta, and the 
Hinton-Edson area in the western part of central Alberta [20]. Aside from these three hot spots, the majority of Alberta has geothermal resources quite suitable for district heating, or geothermal heat pumps. Majorowicz et al. [21] created maps of Canada showing the average temperature at 3.5km, $6.5 \mathrm{~km}$, and $10 \mathrm{~km}$ below ground level. As seen in Figure 2, Alberta has temperatures between $50^{\circ} \mathrm{C}$ and $100^{\circ} \mathrm{C}$ at $3.5 \mathrm{~km}$ below ground level throughout the majority of the province. Although these temperatures are not suitable for electricity production, they can be very useful for heating purposes.

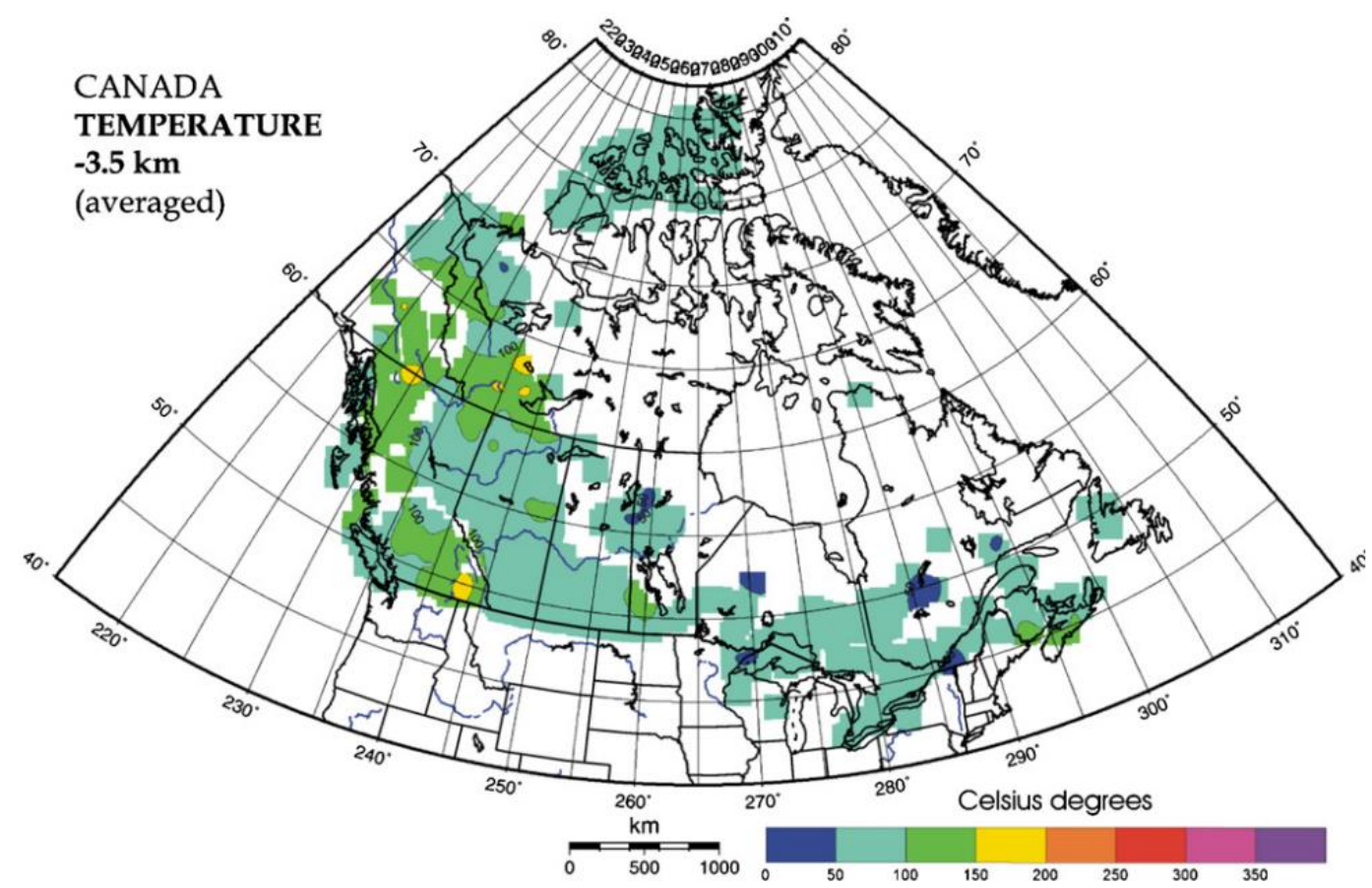

Figure 2: Average temperature at $3.5 \mathrm{~km}$ below surface [21]

Based on the research by Majorowicz and Grasby on geothermal gradients in Western Canada, the majority of wells with a total vertical depth (TVD) of 3500 meters will have a bottom hole temperature in the range of $50^{\circ} \mathrm{C}$ to $100^{\circ} \mathrm{C}$ [21]. The Alberta Energy Regulator lists wells by their total depth (TD), this value represents the total length of the well including any curved sections and is different from TVD [19]. The TVD represents the total vertical distance below surface which the well 
reaches. This value is important for determining the bottom hole temperature from geothermal gradients.

Wells with a depth greater than $2750 \mathrm{~m}$ can be considered for geothermal power, because of localized hot spots and variations in the geothermal gradient throughout the province. Further narrowing down the number of wells available, of the 102,565 wells noted as being suspended, only 5802 wells have a TD greater than $2750 \mathrm{~m}$ [19]. In the absence of TVD values, TD can be used instead, as any well that has at least a $2750 \mathrm{~m}$ TVD will also have a TD greater than $2750 \mathrm{~m}$.

\subsection{Scope of Study}

The objective of this project is to create a tool for the evaluation and optimization of oil and gas wells retrofitted to produce geothermal power, and apply this tool to the retrofit design of a well located in the Hinton region of Alberta. The concentric double pipe downhole heat exchanger has been chosen for this study as it is used in a closed well bore and does not rely on the presence of a hot aquifer to extract heat from. Similar studies have been conducted to predict the temperature of water output from wells. Additionally studies into optimizing the mass flow rate of water through the well have been conducted. This study is set out to create a tool for optimizing both the flow rate, tubing sizes, and depth of well to be utilized.

The method employed in this study is a simplified analysis which utilizes empirical correlations in a forced convection heat transfer model using a control volume method. The simplicity of this method allows the model to be applied to multiple well geometries without the need for a new $3 \mathrm{~d}$ model to be created for each well geometry. The method also allows for multiple flow regimes and design parameters to be quickly compared and graphed. 


\section{Chapter 2 Problem Description and Modeling Procedure}

\subsection{Introduction}

The development of the geothermal retrofit simulation model has gone through three stages of complexity. The first step was a verification that the hot fluid would reach the surface with minimal temperature losses. Microsoft Excel was used to determine the heat loss from the center tube to the cold fluid flowing down the annulus, and the system was analysed as a shell and tube heat exchanger. The model showed that with the use of vacuum insulated tubing, the fluid would lose minimal heat, reaching the surface with almost the same temperature it achieved at the bottom.

A model in MATLAB was created to both simulate the heat loss from the center tube and the heat extracted from the casing wall. This model used a control volume method, and showed that the water flowing down the annulus mirrors the temperature increase of the annulus wall caused by the geothermal gradient. This model neglected the thermal resistance caused by the well casing which separates the fluid from the formation.

Finally, the casing geometry and its thermal resistance was implemented into the model. This change had the largest effect on the annulus fluids bulk temperature profile. At points where a string of casing ended, and the total casing thickness between the fluid and the formation decreased, there is a significant increase in the heat transfer rate to the fluid. This also had an effect on the water flowing upward through the insulated tubing. The temperature difference between the hot fluid and cold fluid is now greater near the surface, resulting in slightly more heat loss from the hot fluid than the previous model predicted. The recovered temperatures are still relatively close to the bottom hole temperature, and show the viability of these systems to recover heat from the earth. 


\subsection{Well Geometry}

When an oil well is drilled, the process is performed in stages called a casing program. Casing is the layers of steel pipe and cement used to strengthen the well, and seal off the inside of the well from the rock formation. The well is drilled to a predetermined depth and cased, then drilled to a deeper depth with a smaller drill bit and cased again. This happens multiple times until the well has reached its total depth [22]. A typical casing program in Alberta contains three to four strings of casing. The first string of casing installed is the conductor pipe, which is placed to a depth of 20 meters to 30 meters and is fully cemented [23]. The conductor pipe is used to keep the well bore open, and allow for drilling fluids to return to the surface.

The surface casing is the second stage in the casing program and is used to protect surface water from contamination. This pipe is cemented in position. A secondary purpose for surface casing is that it provides structural support for installing the remaining strings of casing and provides a location for the blowout preventers to be installed [24]. The depth which the surface casing is installed to is, typically between $200 \mathrm{~m}$ and $600 \mathrm{~m}$, determined by directive 008 from the Alberta Energy Regulator [23].

The intermediate casing is installed after the surface casing, which helps to maintain well bore integrity for the majority of the well, and allows for different drilling fluids to be used for formations with higher pressures or formations which pose a risk of collapsing [24]. The intermediate casing is also cemented in position.

Finally, the production casing is installed and cemented in position. Production casing typically extends to the bottom of the well, although in some wells a section of drilled hole is left open and uncased or a perforated liner is hung into the open hole. In wells where the production casing runs to the bottom of the well bore, holes in the casing are needed to open the well to the petroleum holding formations. These holes are called perforations and are created in the well casing at pre-specified 
points. They are created by detonating an explosive device in the well. These devices aim jets of gasses released from the explosion at the casing wall creating the perforations [22].

\subsection{Equations}

\subsubsection{Concentric Tube Heat Exchanger Feasibility Test}

As an initial test to investigate the feasibility of the studied geothermal system and to determine whether further investigations were warranted, a basic control volume model was created using Microsoft Excel. The test was conducted assuming that the annular fluid heated up at the same rate as the formation. In this case, a linear temperature increase from $20^{\circ} \mathrm{C}$ to $125^{\circ} \mathrm{C}$ was assumed.

The function of the model was to test the heat loss from the hot return water to the cold inlet water through the tubing wall. The density, dynamic viscosity, specific heat, and thermal conductivity of both the hot and cold fluids were calculated using the bulk fluid temperatures of each control volume. An estimated exit temperature for each control volume was used for the hot water along with the calculated exit temperature of the previous control volume to calculate the bulk fluid temperature.

The Reynolds number, Prandtl number, Darcy-Weisbach Frictional factor, and the Nusselt number are calculated according to the properties of water at the bulk fluid temperature of the control volume. The Nusselt number is used to find the heat transfer coefficient for the thermal resistor on both the hot and cold side of the tubing wall. These thermal resistor values along with the thermal resistance of the tubing wall itself are then used to calculate the heat loss from the hot fluid to the cold fluid.

The final model does not include the transient nature of the real-life system. The values output by the model are only valid at the initial stage of operation. Additional, time variant parameters are needed to predict the temperature change of the rock formations, additionally detailed thermal properties of each formation the well passes through are needed. These calculations are beyond the 
scope of this report, but are an important topic for future research. Converting the current model to a transient model will help predict the longevity of the systems, as well as allowing further optimization of the system.

The values chosen for this initial test do not relate to any specific well, but are generalized based on the design brief, the input values can be found in Table 1. A vacuum insulated tubing (VIT) string has been chosen to fit within a casing string with an internal radius of $0.0889 \mathrm{~m}$. VIT is a commercial product used in the Oil and Gas industry. It is generally used for steam injection wells in the Athabasca Oil Sands, where it is specialized for maintaining high quality steam over large distances by drastically reducing the thermal conductivity across the pipe walls when compared to conventional steel tubulars. The specific VIT used has been selected from Andmir, a company specializing in enhanced oil recovery technologies. This VIT has an outside radius of $0.05715 \mathrm{~m}$, an inside radius of $0.0381 \mathrm{~m}$ and a thermal conductivity between 0.002 and $0.02 \mathrm{~W} / \mathrm{m}^{\circ} \mathrm{C}[25]$. In the calculation, the conductivity of the VIT was taken to be 0.02 $\mathrm{W} / \mathrm{mK}$ in order give a conservative estimate of the outlet temperature. To compare the effectiveness of VIT to conventional stainless steel tubing, a comparative test has been run using the same dimension tubing, but with a thermal conductivity of stainless steel $\left(15.6 \mathrm{~W} / \mathrm{m}^{\circ} \mathrm{C}[26]\right)$.

The temperature gradient of $0.035^{\circ} \mathrm{C} / \mathrm{m}$ corresponds to the well depth of $3000 \mathrm{~m}$ with a surface temperature of $20^{\circ} \mathrm{C}$ and a bottom hole temperature of $125^{\circ} \mathrm{C}$. 
Table 1: Feasibility Test Input Parameters

$\begin{array}{ll}\text { Depth, } d(\mathrm{~m}) & 3000\end{array}$

Tubing inside radius, $R_{1}(\mathrm{~m}) \quad .0381[25]$

Tubing outside radius, $R_{2}(\mathrm{~m}) \quad 0.05715[25]$

Casing inside radius, $R_{\mathbf{3}}(\mathrm{m}) \quad 0.0889\left(7^{\prime \prime}\right)$

Vacuum Insulated Tubing Thermal Conductivity, $\mathrm{k}\left(\mathrm{W} / \mathrm{m}^{\circ} \mathrm{C}\right) \quad 0.02[25]$

Stainless Steel Thermal Conductivity, $\boldsymbol{k}_{s s}\left(\mathrm{~W} / \mathrm{m}^{\circ} \mathrm{C}\right) \quad 15.6[26]$

Mass Flow Rate, $\dot{\boldsymbol{m}}(\mathrm{kg} / \mathrm{s})$

$\begin{array}{ll}\text { Temperature Gradient }\left({ }^{\circ} \mathrm{C} / \mathrm{m}\right) & 0.035\end{array}$

$\begin{array}{ll}\text { Surface Temperature, } T_{s}\left({ }^{\circ} \mathrm{C}\right) & 20\end{array}$

As can be seen in Figure 3, the concentric double pipe heat exchanger shows great potential when VIT is used for the center tube, whereas it is demonstrated that conventional stainless steel tubing is not suitable for a double pipe heat exchanger. With VIT used, only $2^{\circ} \mathrm{C}$ is predicted to be lost from the return fluid. The return water flowing through a stainless-steel tubing loses $98^{\circ} \mathrm{C}$ to the cold water entering the system. 


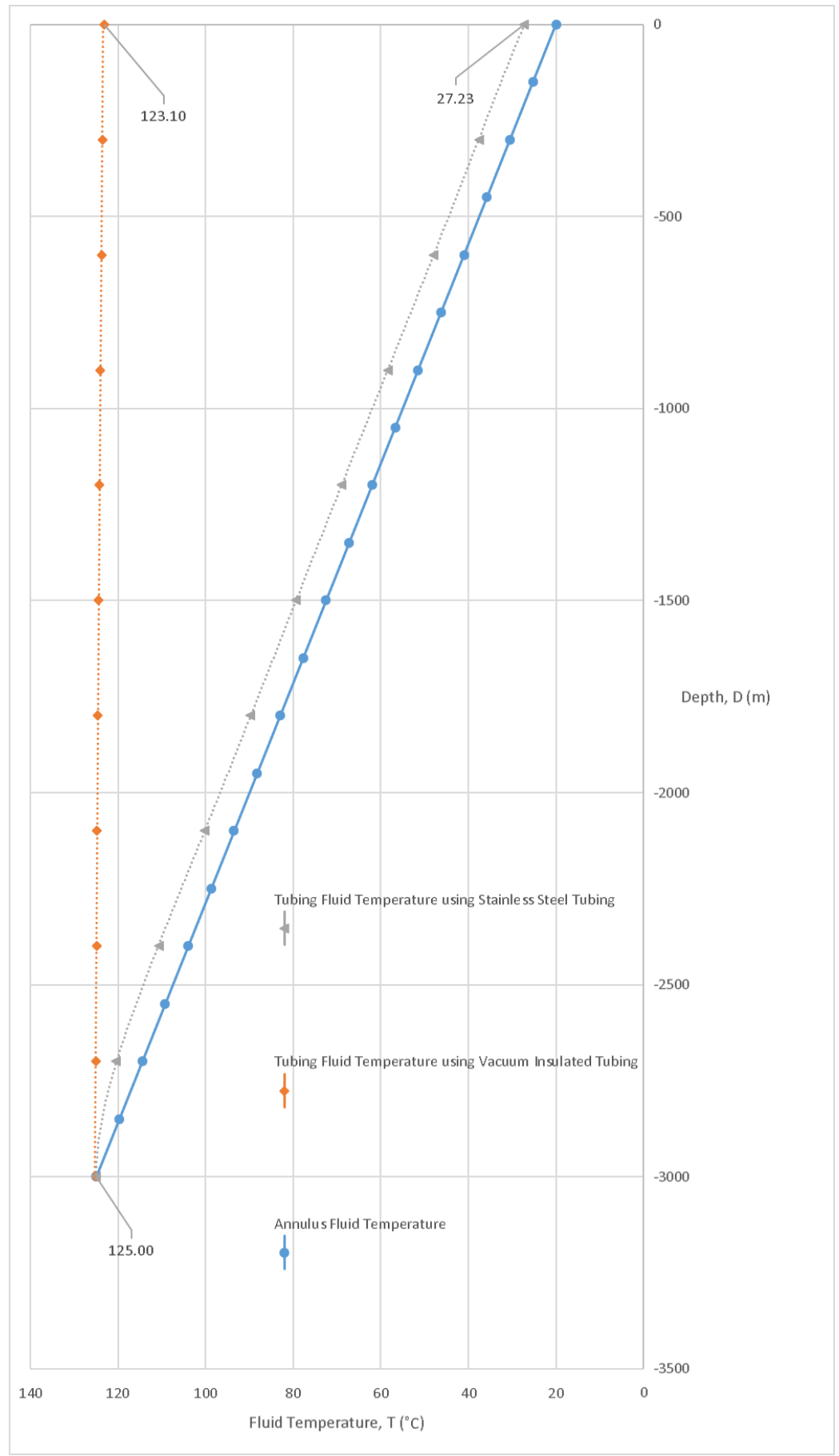

Figure 3: Feasibility test comparing heat loss from return fluid to annulus fluid between vacuum insulated tubing and stainless steel tubing 


\subsubsection{Control Volume Analysis}

The well can be divided into a finite number of vertical control volumes, separating the annulus and tubing as seen in Figure 4. The bulk fluid temperature at each control volume can be solved in order following the direction of flow, from the top annulus control volume down to the bottom annulus control volume. Then, following the returning fluid, up the center tubing from the bottom control volume to the surface tubing control volume. For the first iteration solving the annular fluid temperature, the fluid temperature of every tubing control volume is assumed to be the bottom hole temperature. The surface tubing control volume's bulk temperature is considered the output temperature. The number of control volumes, $n$, was increased until the outlet temperature converged on a value. The number of control volumes used for the test well is 12000 , resulting in a $\Delta x$ of $0.25 \mathrm{~m}$. This value was found with a grid convergence test, the test was conducted until the exit fluid temperature converged to three significant digits. The effect of internal heat generation caused by friction has been assumed negligible in these models. This is because of the large heat flow which is being targeted compared to the size of available pumps. 


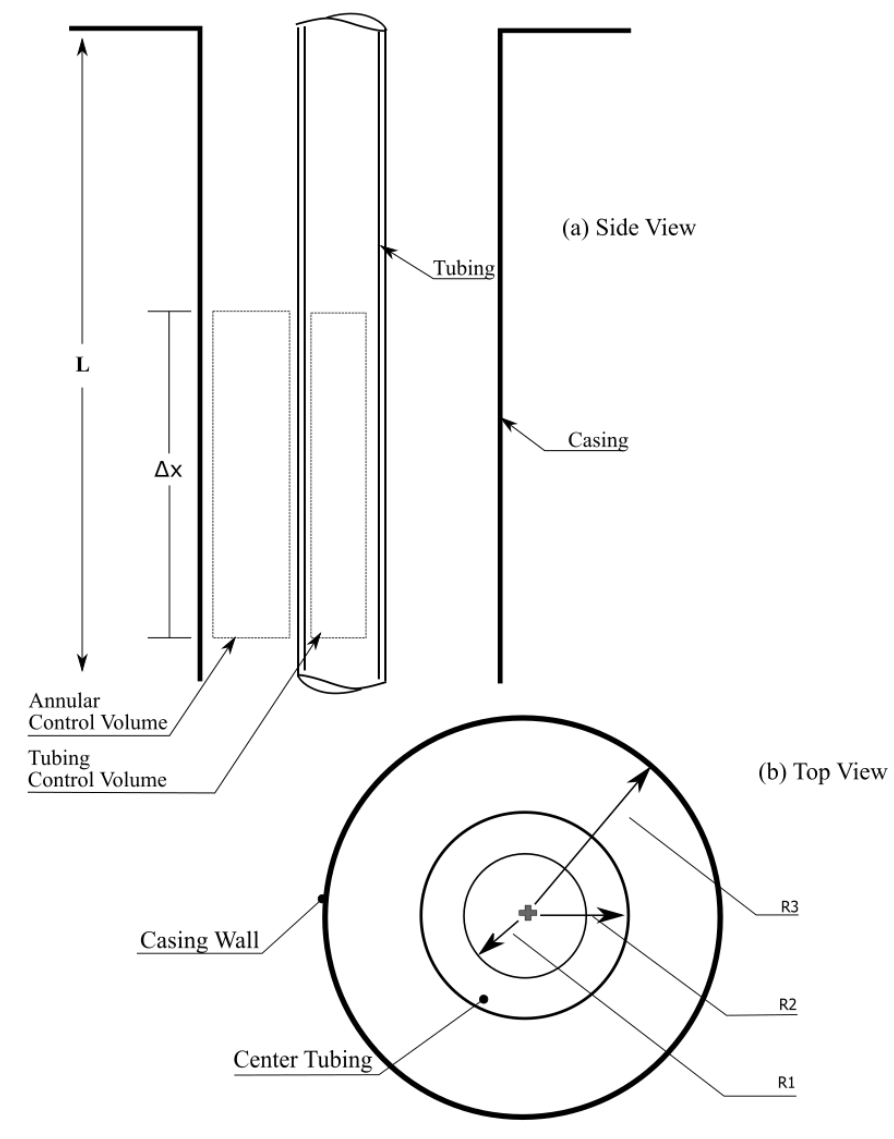

Figure 4: Well Diagram, Ignoring Casing Geometry

The bulk fluid temperature at each control volume is solved through a heat energy balance. Each annulus control volume has three incoming heat flows, and one outflow as seen in Figure 5 . In Figure 5 and Figure $6, T_{R}$ is the formation (rock) temperature, $T_{c}$ is the temperature of the cold flow on the annulus side, $T_{h}$ is the temperature of the hot flow inside the tubing, and $j$ is the current control volume. 


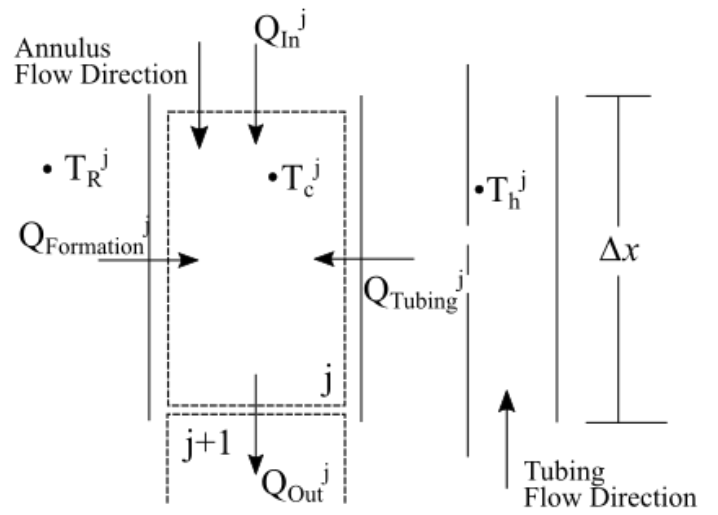

Figure 5: Annular Side Control Volume Diagram

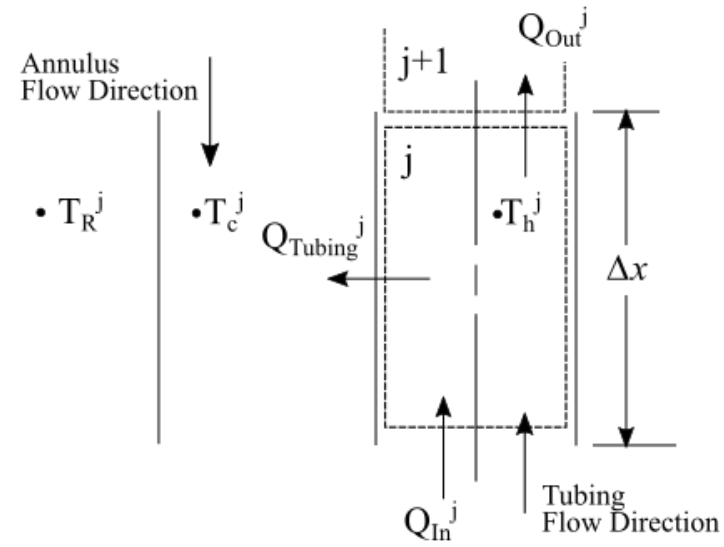

Figure 6: Tubing Side Control Volume Diagram

This initial control volume model makes the assumption that the inside surface of the well casing is in thermal equilibrium with the rock formation. The effect this assumption will have on the model is an inflated value of heat flow from the formation into the fluid. This assumption will be addressed in a Section 2.3.2. 
The geothermal well has been simulated using a control volume model. The geothermal system is divided into $n$ control volumes of length $\Delta x$. When considering the $j^{\text {th }}$ control volume of the system, the steady state energy balance of the annulus fluid can be written as:

$$
Q_{\text {in }}+Q_{\text {formation }}+Q_{\text {tubing }}-Q_{\text {out }}=0
$$

Where,

$$
\begin{gathered}
Q_{\text {in }}=\dot{m} C_{p_{c}^{j}}^{j-1} T_{c}^{j-1} \\
Q_{\text {formation }}=h_{c}^{j} A_{c}\left(T_{R}^{j}-T_{c}^{j}\right) \\
Q_{\text {tubing }}=u_{t}^{j} A_{t}\left(T_{h}^{j}-T_{c}^{j}\right) \\
Q_{\text {out }}=\dot{m} C_{p_{c}}^{j} T_{c}^{j}
\end{gathered}
$$

The steady state energy balance of the annulus fluid can be expanded as:

$$
h_{c}^{j} A_{c}\left(T_{R}^{j}-T_{c}^{j}\right)+\dot{m} C_{p_{c}}^{j-1} T_{c}^{j-1}-\dot{m} C_{p_{c}}^{j} T_{c}^{j}+u_{t}^{j} A_{t}\left(T_{h}^{j}-T_{c}^{j}\right)=0
$$

The value of the bulk temperature of the annulus fluid for the $j^{\text {th }}$ control volume is needed to move on and solve the following control volume. Rearranging equation 6 , the bulk fluid temperature can be solved as:

$$
T_{c}^{j}=\frac{h_{c}^{j} A_{c} T_{R}^{j}+\dot{m} C_{p_{c}}^{j-1} T_{c}^{j-1}+u_{t}^{j} A_{t} T_{h}^{j}}{h_{c}^{j} A_{c}+\dot{m} C_{p_{c}}^{j}+u_{t}^{j} A_{t}}
$$

Where $A_{t}$ is the surface area of the tubes outside wall,

$$
A_{t}=2 \pi R_{2} \Delta x
$$

And $A_{c}$ is the inside surface area of the casing wall,

$$
A_{c}=2 \pi R_{3} \Delta x
$$


The thermal transmittance or $u_{t}$ value of the $j^{\text {th }}$ control volume is found by combining the annulus side convection resistor, the tubing wall resistor and the tubing side convection resistor.

$$
Q_{\text {tubing }}=\frac{T_{h}^{j}-T_{c}^{j}}{\sum R}=u_{t}^{j} A_{t}\left(T_{h}^{j}-T_{c}^{j}\right)
$$

Solving for $u_{t}^{j} A_{t}$ yields:

$$
u_{t}^{j} A_{t}=\frac{1}{\sum R}=\left[\frac{1}{2 \pi R_{2} \Delta x h_{c}^{j}}+\frac{\ln \left(\frac{R_{2}}{R_{1}}\right)}{2 \pi k_{t} x}+\frac{1}{2 \pi R_{1} \Delta x h_{h}^{j}}\right]^{-1}
$$

In order to solve for both the bulk temperature and the thermal transmittance the heat transfer coefficient of both the hot fluid, $h_{h}$, and cold fluid, $h_{c}$, need to be known. The heat transfer coefficients can be found using the Nusselt number $(N u)$, fluid thermal conductivity $(k)$, and hydraulic diameter $\left(D_{H}\right)$.

$$
h=\frac{k^{j}}{D_{h}} N u^{j}
$$

$\mathrm{Nu}$, the Nusselt number is the dimensionless convection heat transfer coefficient displaying the ratio of convection to conduction within a fluid layer, a larger Nusselt number is the result of more effective convection within the fluid layer. The values needed to solve for the Nusselt number are the Reynolds number $(R e)$, Prandtl number $(\operatorname{Pr})$, and the Darcy-Weisbach friction factor $(f)$. The Nusselt number can found through a number of different equations to varying degrees of accuracy. The DittusBoelter equation, the Gnielski equation, and an exact relationship for laminar flow are used.

Dittus-Boelter Equation [27]:

$$
N u=0.023 \operatorname{Re}^{0.8} \operatorname{Pr}^{n}\left(\begin{array}{c}
0.7 \leq \operatorname{Pr} \leq 160 \\
\operatorname{Re}>10000
\end{array}\right)
$$

Where,

$$
n=0.4 \text { for heating of the fluid, and } n=0.3 \text { for cooling of the fluid }
$$


Gnielski Equation [27]:

$$
N u=\frac{\left(f^{j} / 8\right)\left(R e^{j}-1000\right) P r^{j}}{1+12.7\left(f^{j} / 8\right)^{0.5}\left(\left(\operatorname{Pr}^{j}\right)^{2 / 3}-1\right)}\left(\begin{array}{c}
0.5 \leq \operatorname{Pr} \leq 2000 \\
3 \times 10^{3}<\operatorname{Re}<5 \times 10^{6}
\end{array}\right)
$$

Laminar flow in circular tube with constant surface temperature [27]:

$$
N u=3.66(R e \leq 2300)
$$

The Reynolds number is a dimensionless number representing the ratio of inertia forces to viscous force, its value is useful in describing the type of flow, either laminar, transitional, or turbulent. The Reynolds number, $R e$, is solved as:

$$
R e=\frac{\rho V_{\text {avg }} D_{h}}{\mu}=\frac{\dot{m} D}{A \mu}
$$

When solved for the annulus control volume, the equation becomes:

$$
R e_{\text {annulus }}=\frac{\dot{m} D_{h}}{A_{\text {annulus }} \mu_{c}^{j}}
$$

And for the tubing control volume,

$$
\operatorname{Re}_{\text {tubing }}=\frac{\dot{m} D}{A_{\text {tubing }} \mu_{h}^{j}}
$$

Where $\mu$ is the dynamic viscosity of the bulk fluid, $D$ and $D_{h}$ is the diameter and hydraulic diameter respectively, and $A_{\text {annulus }}$ and $A_{\text {tubing }}$ are the cross-sectional areas. The hydraulic diameter is the difference between the outside and inside diameters of the annulus, in this case the inside diameter of the casing and the outside diameter of the VIT.

$$
D_{h}=D_{3}-D_{2}=2\left(R_{3}-R_{2}\right)
$$


The Prandtl number represents the ratio of momentum diffusivity to thermal diffusivity and is calculated as:

$$
\operatorname{Pr}=\frac{\mu^{j} C_{p}^{j}}{k^{j}}
$$

The Darcy-Weisbach friction factor can be calculated using the Colebrook-White equation [28]. The Colebrook-White equation combines the smooth wall and fully rough relations into an interpolated formula, solving the equation requires an iterative method.

$$
\frac{1}{\sqrt{f}}=-2 \log \left(\frac{\epsilon^{j}}{3.7 D_{e f f}}+\frac{2.51}{R e^{j} \sqrt{f}}\right)
$$

$D_{\text {eff }}$ is a modified hydraulic diameter for use in concentric annular flow, the annular hydraulic diameter is multiplied by a correctional factor $\zeta[28]$. This correctional factor is only valid when used to calculate frictional factors, the regular hydraulic diameter should be used for all other calculations.

$$
R e_{e f f}=\frac{R e_{h}}{\zeta}
$$

Where,

$$
\zeta=\frac{\left(R_{3}-R_{2}\right)^{2}\left(\left(R_{3}\right)^{2}-\left(R_{2}\right)^{2}\right)}{\left(R_{3}\right)^{4}-\left(R_{2}\right)^{4}-\frac{\left(\left(R_{3}\right)^{2}-\left(R_{2}\right)^{2}\right)^{2}}{\ln \left(R_{3} / R_{2}\right)}}
$$

Similar to solving the bulk fluid temperature in the $j^{\text {th }}$ control volume of the annulus. The energy balance of $j^{\text {th }}$ control volume within the tube is:

$$
\dot{m} C_{p_{h}}^{j+1} T_{h}^{j+1}=u_{t}^{j} A_{t}\left(T_{h}^{j}-T_{c}^{j}\right)+\dot{m} C_{p_{h}}^{j} T_{h}^{j}
$$

Solving for the tubing bulk fluid temperature of the $j^{\text {th }}$ control volume: 


$$
T_{h}^{j}=\frac{\dot{m} C_{p_{h}}^{j+1} T_{h}^{j+1}+u_{t}^{j} A_{t} T_{c}^{j}}{u_{t}^{j} A_{t}+\dot{m} C_{p_{h}}^{j}}
$$

Once all of the bulk fluid temperatures are known for the control volume system the total heat flow of the system can be found using the equation:

$$
\dot{Q}_{\text {total }}=\dot{m}\left(C_{p_{h}}^{1} T_{h}^{1}-C_{p_{c}}^{1} T_{c}^{1}\right)
$$

The pumping power required is found by first evaluating the head loss of each control volume in both the annulus and the tubing with the equations:

$$
\begin{aligned}
h_{f_{\text {annulus }}^{j}}^{j} & =f_{\text {annulus }}^{j} \frac{\Delta x}{D_{h}} \frac{\left(V_{\text {annulus }}^{j}\right)^{2}}{2 g} \\
h_{f_{\text {tubing }}}^{j} & =f_{\text {tubing }}^{j} \frac{\Delta x}{D} \frac{\left(V_{\text {tubing }}^{j}\right)^{2}}{2 g}
\end{aligned}
$$

Where $V_{\text {annulus, }}^{j}$ the average fluid velocity of the $j^{\text {th }}$ control volume for the annulus is:

$$
V_{\text {annulus }}^{j}=\frac{\dot{m}}{\rho_{c}^{j} A_{\text {annulus }}}
$$

And for the tubing side:

$$
V_{\text {tubing }}^{j}=\frac{\dot{m}}{\rho_{h}^{j} A_{\text {tubing }}}
$$

To solve for the pumping power required:

$$
P_{\text {pump }}=\dot{m}\left(\sum_{j=1}^{n} h_{f_{\text {annulus }}}^{j}+\sum_{j=1}^{n} h_{f_{\text {tubing }}}^{j}\right) g
$$


Using the same input parameters as found in Table 1, it is predicted using the MATLAB program that an output temperature of $123^{\circ} \mathrm{C}$ losing a total of $2^{\circ} \mathrm{C}$ from the return fluid to the incoming cold water. Further results can be seen in Table 2. The annulus fluid mirrors the temperature increase of the casing wall, reaching a peak temperature of $124.96^{\circ} \mathrm{C}$, just $0.04^{\circ} \mathrm{C}$ short of the bottom hole temperature. This behavior can be seen in the temperature profiles of the bulk fluid found in Figure 7 and Figure 8 .

The feasibility model and control volume model are in very close agreement with each other, the slight difference between the two models results can be attributed to the small difference in water temperature entering the tubing string. This difference of $0.04^{\circ} \mathrm{C}$ is almost the same value as the difference in water temperature recovered at surface, $0.03^{\circ} \mathrm{C}$. The feasibility model did not calculate the heat flow into the working fluid, assuming the fluid would reach the bottom hole temperature, whereas the MATLAB model calculates this heat flow.

Table 2: MATLAB model example results.

Return Temperature, $T^{1}{ }_{h}\left({ }^{\circ} \mathrm{C}\right)$

Peak Fluid Temperature, $T^{n}{ }_{c}\left({ }^{\circ} \mathrm{C}\right)$ 


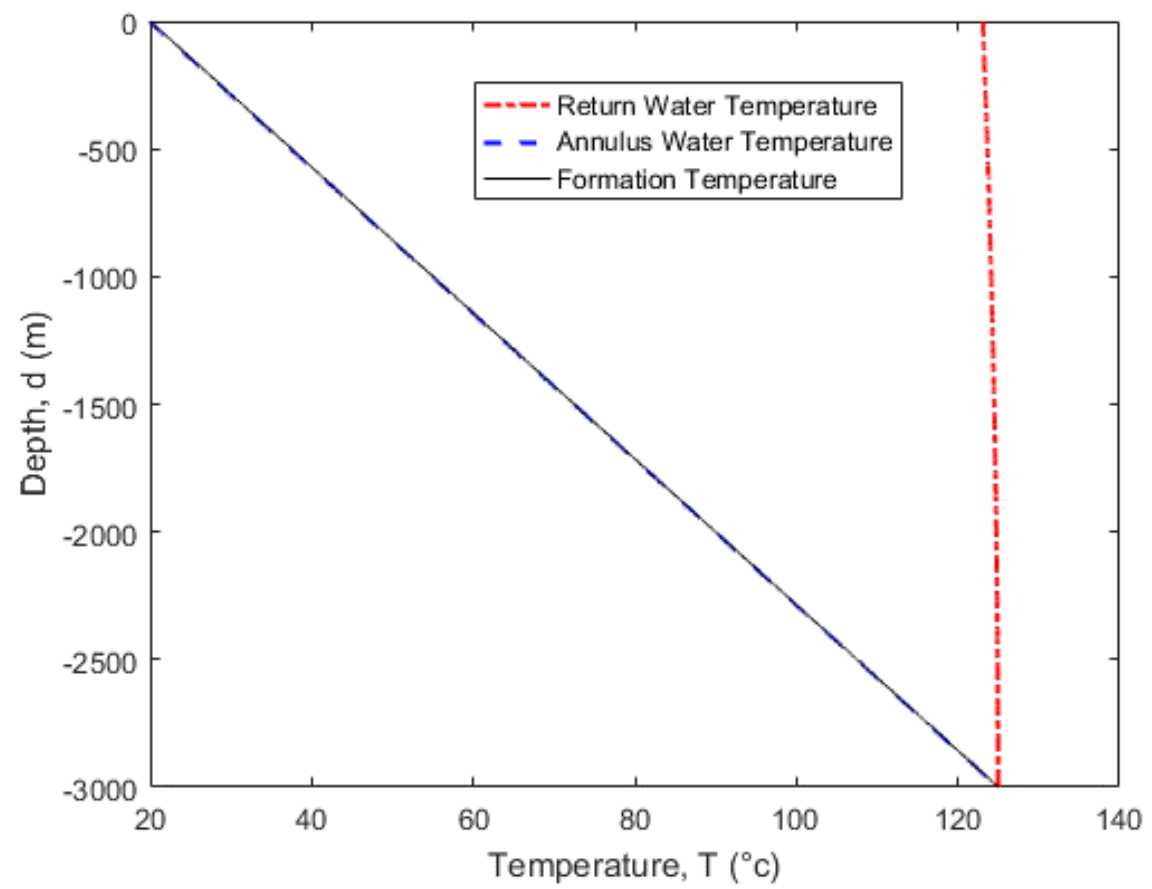

Figure 7: Fluid temperature profile of the MATLAB model example results.

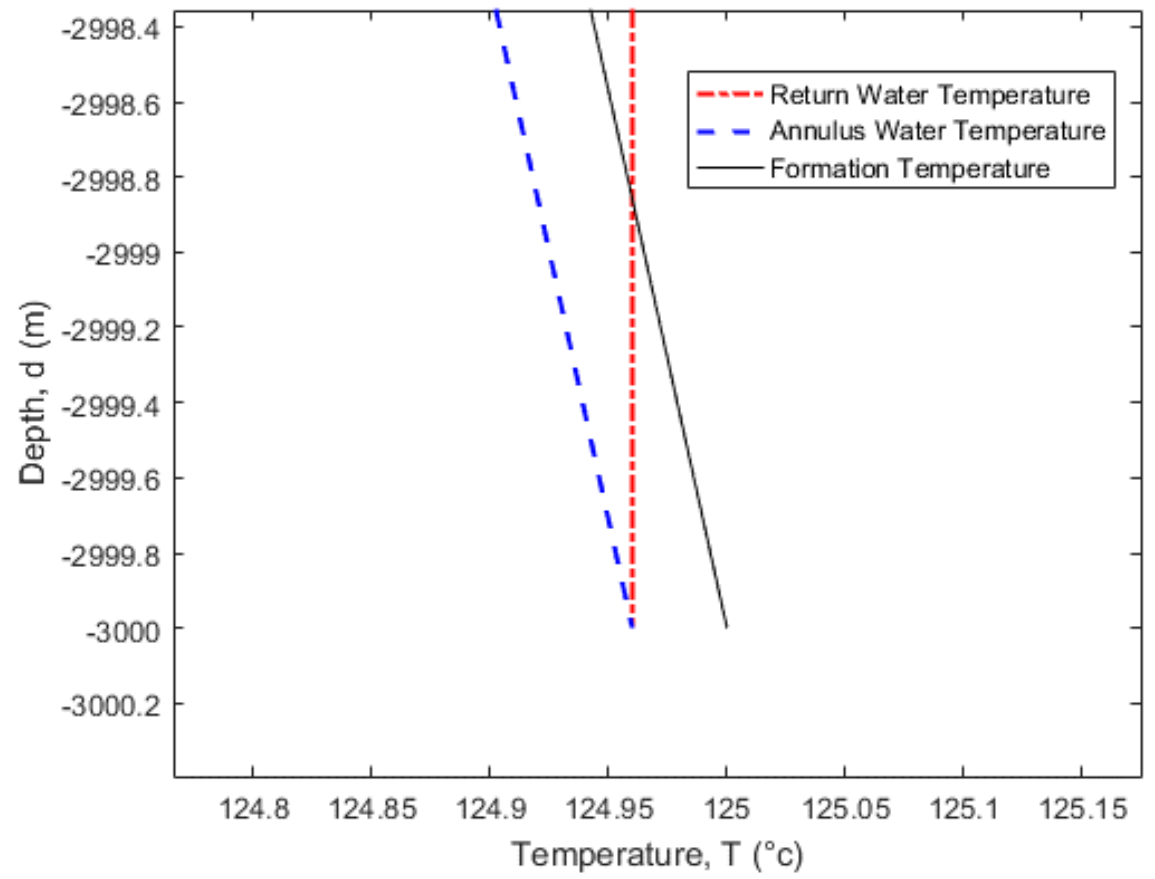

Figure 8: Fluid temperature profile of the MATLAB model example at bottom hole. 


\subsubsection{Expanding the Control Volume Analysis}

The addition of the well casing thermal resistor into the MATLAB model will increase the accuracy of the modeled fluid temperatures. This addition removes the assumption that the inside surface of the well casing is the same as the temperature of the formation. The assumption is now that the surface of the outside of the well casing, and the formation are in thermal equilibrium.

For the inclusion of the well casing to act as a thermal resistor, $Q_{\text {formation }}$ now becomes,

$$
Q_{\text {formation }}=\frac{T_{R}^{j}-T_{c}^{j}}{\sum R}=u_{c}^{j} A_{c}\left(T_{R}^{j}-T_{C}^{j}\right)
$$

Where,

$u_{c}^{j} A_{c}=\frac{1}{\sum R}=\left[\frac{\ln \frac{R_{11}}{R_{10}}+\ln \frac{R_{9}}{R_{8}}+\ln \frac{R_{7}}{R_{6}}+\ln \frac{R_{5}}{R_{4}}}{2 \pi \Delta x k_{\text {concrete }}}+\frac{\ln \frac{r_{10}}{r_{9}}+\ln \frac{r_{8}}{r_{7}}+\ln \frac{r_{6}}{r_{5}}+\ln \frac{r_{4}}{r_{3}}+\ln \frac{r_{2}}{r_{1}}}{2 \pi \Delta x k_{\text {steel }}}+\frac{1}{h_{c}^{j} A_{c}}\right]^{-1}$

Where, as seen in Figure $9, R_{11}$ through $R_{3}$ are the radiuses of the different layers of casing. $R_{3}$ being the inner surface of the casing, and $R_{11}$ being the outer surface in contact with the formation. 


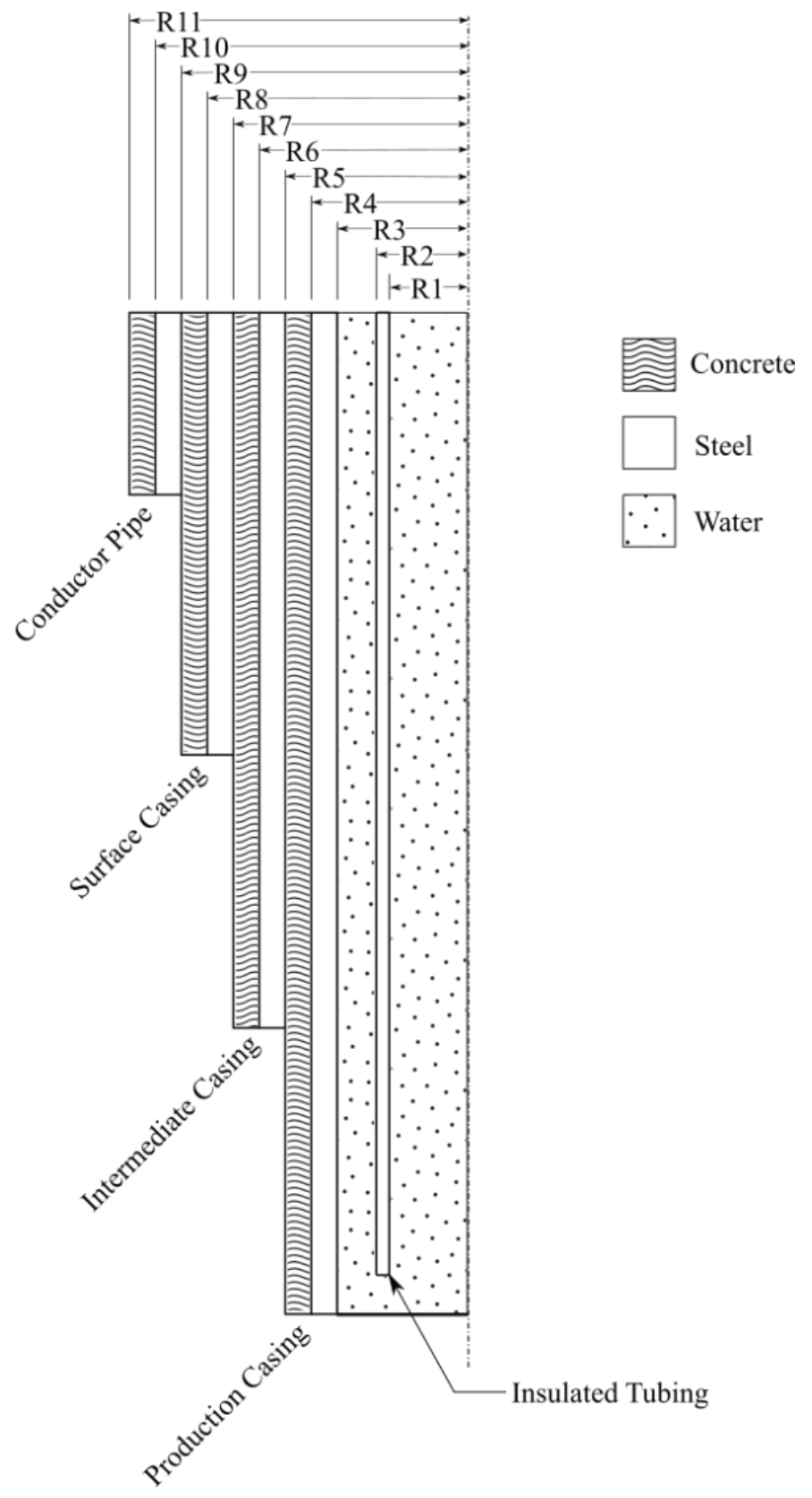

Figure 9: Well Diagram Including Casing Geometry (left side only)

To solve for the bulk fluid temperature with the inclusion of the well casing thermal resistor, the equation now becomes:

$$
T_{c}^{j}=\frac{u_{c}^{j} A_{c} T_{R}^{j}+\dot{m} C_{p_{c}}^{j-1} T_{c}^{j-1}+u^{j} A_{t} T_{h}^{j}}{u_{c}^{j} A_{c}+\dot{m} C_{p_{c}}^{j}+u_{t}^{j} A_{t}}
$$


Using the previously used parameters found in Table 1, in addition to the casing program found in Table 3, the MATLAB model now presents the results which can be found in Table 4 . The temperature profile of the bulk fluid can be found in Figure 10. The updated results show a slight increase in required pumping power from 9.19MW to $9.20 \mathrm{MW}$, this increase is caused by the lower bulk temperatures and subsequent higher densities. The exit fluid temperature has dropped from $123^{\circ} \mathrm{C}$ to $114^{\circ} \mathrm{C}$ as a result of the lower temperature achieved at the bottom hole, $116^{\circ} \mathrm{C}$ compared to $125^{\circ} \mathrm{C}$. A noticeable increase in the heat transfer from the formation through the casing to the fluid is found where each string of casing ends, excluding the conductor pipe due to its relatively short length of $65 \mathrm{~m}$. This increase is a result of the thermal resistor shrinking in value as layers of casing are removed.

Table 3: Casing Program used for MATLAB model including well casing thermal resistor example results.

\begin{tabular}{c|cccc} 
& $\begin{array}{c}\text { CASING } \\
\text { DEPTH }(\mathbf{m})\end{array}$ & $\begin{array}{c}\text { CONCRETE } \\
\text { OUTSIDE DIAMETER } \\
(\mathbf{m})\end{array}$ & $\begin{array}{c}\text { PIPE OUTSIDE } \\
\text { DIAMETER }(\mathbf{m})\end{array}$ & $\begin{array}{c}\text { PIPE } \\
\text { INSIDE } \\
\text { DIAMETER }(\mathbf{m})\end{array}$ \\
\hline CONDUCTOR PIPE & 65 & $R_{11}=0.3302$ & $R_{10}=0254$ & 0.2032 \\
SURFACE & 800 & $R_{9}=0.2032$ & $R_{8}=0.16985$ & 0.154625 \\
INTERMEDIATE & 2000 & $R_{7}=0.154625$ & $R_{6}=0.12225$ & 0.108 \\
PRODUCTION & 3000 & $R_{5}=0.108$ & $R_{4}=0.09525$ & $R_{3}=0.0889$
\end{tabular}

Table 4: MATLAB model including well casing thermal resistor results.

Return Temperature, $T^{1}{ }_{h}\left({ }^{\circ} \mathrm{C}\right)$

Peak Fluid Temperature, $T^{n}{ }_{c}\left({ }^{\circ} \mathrm{C}\right)$

Required Pumping Power, $P_{\text {pump }}$ (MW)

Heat Flow, $Q_{\text {total }}(\mathrm{MW})$
113.51

115.76

9.20

2.35 


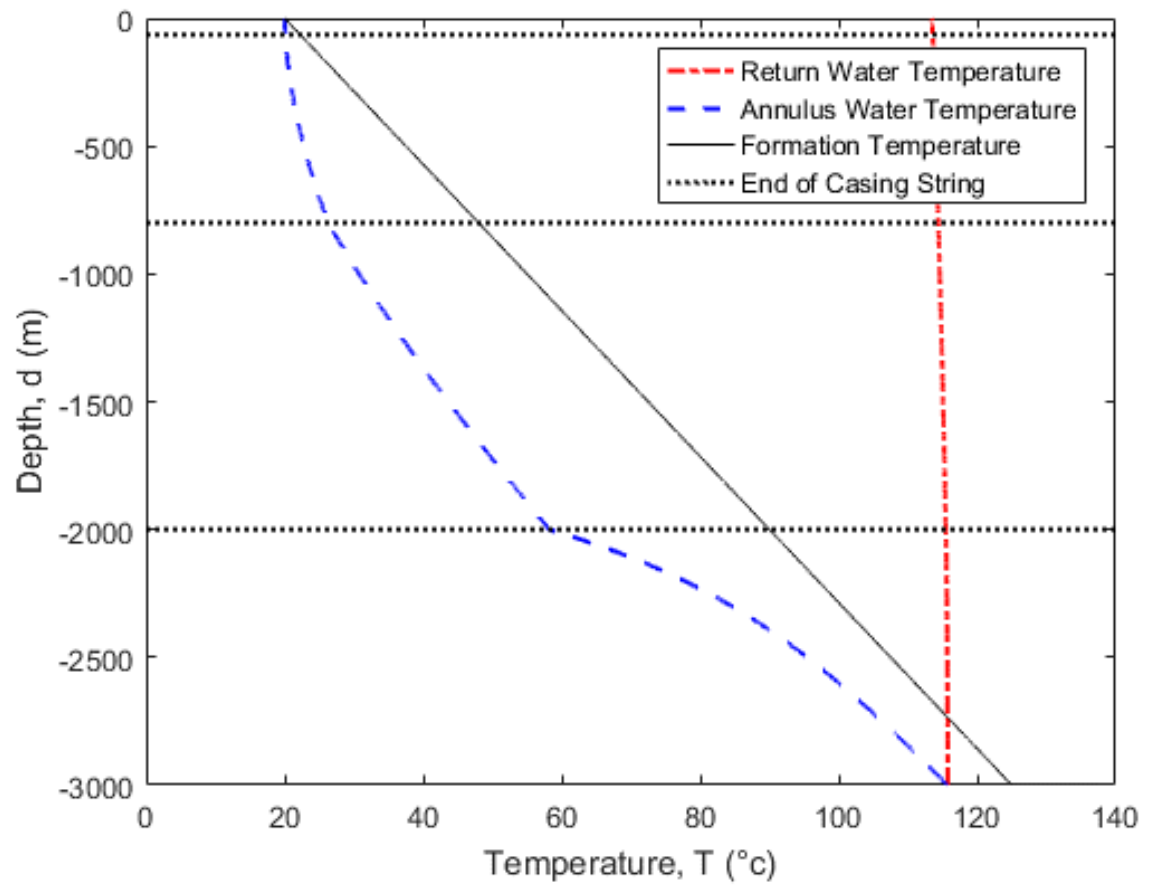

Figure 10: Fluid temperature profile of the MATLAB model including well casing thermal resistor example results.

The assumption that internal heat generation is negligible, was based on the prediction that the pumping power required to overcome the frictional losses would be significantly lower than the generated heat. In the results found in Table 4, the pumping power is almost four times the generated heat. This was not an expected outcome, but can be explained by the test wells input parameter of $6 \mathrm{~kg} / \mathrm{s}$ mass flow rate. This mass flow rate produced a heat flow which is almost twice as large as the heat flow needed for the final design. Scaling back the mass flow rate should significantly reduce the frictional losses. It is still expected that, to produce a $1.25 \mathrm{MW}$ heat flow, the internal heat generated by frictional losses will be negligible for any viable designs. 


\section{Chapter 3 Results and Discussion}

\subsection{Introduction}

A suspended oil well located near Hinton, Alberta has been selected as a candidate well for a geothermal retrofit system. Three different designs for converting the suspended oil well into a geothermal well have been proposed. These designs have been modeled at their optimum operating configuration by modifying the mass flow rate and VIT dimensions. The designs are optimized to produce their maximum net power, an optimization for most profitable operation would be a better alternative, but the cost of electricity and sale price for heat energy are unknown at this point. Additionally, the designs have been modeled at the operating conditions required to produce a $1.25 \mathrm{MW}$ heat flow.

Because of the drastically different TD found in the candidate well $(5624 \mathrm{~m})$, compared to the test well $(3000 \mathrm{~m})$, the resulting pumping powers are much higher than anticipated. Because of the large pumping powers, neglecting internal heat generation is not a valid assumption with out further investigation.

The results presented in Section 3.5 maintain the assumption of no internal heat generation. The required changes to the equations to include internal heat generation are presented in Section 3.6, followed by a demonstration of the effects this addition has on the results of Design 1 in Table 19. These updated results show that the results for Design 1 overestimate the mass flow rate of the optimized well by $51 \%$ and the pumping power by $98 \%$. These are large errors, and invalidates the initial results found in Section 3.5 until further simulations are conducted. 


\subsection{Well Information}

The candidate well that has been selected is located near the town of Hinton, Ab. Drilling began on the well in 1973, and was in operation until August 2016. The casing program used four strings of casing; a conductor pipe, surface casing, intermediate casing, and production casing. The well reaches a TVD of $5624 \mathrm{~m}$, the depths of each casing string can be found in Table 5 and the casing radiuses can be

found in Table 6. Due to lack of available information, the concrete diameter is assumed to be the same as the previous casing strings internal diameter, and the steel casing wall thicknesses are assumed.

The well has 33 perforated sections, the highest of which is located at a depth of $2816 \mathrm{~m}$. A drill stem test at the bottom of the borehole measured the formation temperature to be $158^{\circ} \mathrm{C}$, as seen in 
Table 7 this bottom hole temperature results in a geothermal gradient of $0.024^{\circ} \mathrm{C} / \mathrm{m}$ assuming a surface temperature of $20^{\circ} \mathrm{C}$.

Table 5: Casing Strings Measured Depths

Casing String

Conductor Pipe

Surface Casing Intermediate Casing

Production Casing
String MD (m)

65

1188

3542

5624

Table 6: Candidate Well Casing Radii

\begin{tabular}{lccc} 
& $\begin{array}{c}\text { CONCRETE OUTSIDE } \\
\text { DIAMETER }(\mathbf{m})\end{array}$ & $\begin{array}{c}\text { PIPE OUTSIDE } \\
\text { DIAMETER }(\mathbf{m})\end{array}$ & $\begin{array}{c}\text { PIPE INSIDE } \\
\text { DIAMETER }(\mathbf{m})\end{array}$ \\
\hline CONDUCTOR & $R_{11}=0.33020[29]$ & $R_{10}=0.25400$ & $R_{9}=0.241300$ \\
PIPE & & & \\
SURFACE & & $R_{8}=0.16985$ & $R_{7}=0.153100$ \\
INTERMEDIATE & & $R_{6}=0.12225$ & $R_{5}=0.107125$ \\
PRODUCTION & & $R_{4}=0.08890$ & $R_{3}=0.072645$
\end{tabular}


Table 7: Formation Temperature Gradient Information

$\begin{array}{ll}\text { Bottom Hole Temperature, } \boldsymbol{T}_{b h}\left({ }^{\circ} \mathrm{C}\right) & 158 \\ \text { Surface Temperature, } T_{s}\left({ }^{\circ} \mathrm{C}\right) & 20 \\ \text { TVD, } \boldsymbol{D}(\mathrm{m}) & 5624 \\ \text { Top Perforation Depth, }(\mathrm{m}) & 2816 \\ \text { Geothermal Gradient, }\left({ }^{\circ} \mathrm{C} / \mathrm{m}\right) & 0.024 \\ \text { Fluid Input Temperature }\left({ }^{\circ} \mathrm{C}\right) & 40\end{array}$

\subsection{Proposed Designs}

The concentric double pipe heat exchanger geothermal system relies on the well bore being closed off from the formation. This is not a common condition for suspended oil and gas wells to be found in, including this candidate well. In order for these wells to produce oil and gas, there is a need for perforations in the casing to open the well bore to the formation. To remedy this for geothermal use, three designs are proposed and modeled. Each design is tested to find its optimum operation condition, looking for the maximum net energy produced. In addition, each well is configured to produce the requested $1.25 \mathrm{MW}$ heat flow.

Each well design will utilize the VIT specifications found in Table 8. Each model of VIT has the same range of apparent $k$ factor, $0.002 \leq \lambda \leq 0.02 \mathrm{~W} / \mathrm{m}^{\circ} \mathrm{C}$. The conservative value of $0.02 \mathrm{~W} / \mathrm{m}^{\circ} \mathrm{C}$ is used as the value for each model.

Table 8: VIT dimensions [25].

\begin{tabular}{l|lll}
\multicolumn{1}{c}{ MODEL: } & $\mathbf{5 . 5} \times \mathbf{4 . 5}$ & $\mathbf{4 . 5 \times 3 . 5}$ & $\mathbf{3 . 5} \mathbf{2 . 3 7}$ \\
\hline INSIDE RADIUS, $\boldsymbol{R}_{\mathbf{1}}(\mathrm{M})$ & 0.0508 & 0.0381 & 0.0126675 \\
OUTSIDE RADIUS, $\boldsymbol{R}_{\mathbf{2}}$ (M) & 0.06985 & 0.05715 & 0.022225 \\
$\begin{array}{l}\text { APPARENT K FACTOR, } \boldsymbol{K} \\
\left.\text { (W/M } / \mathrm{M}^{\circ} \mathrm{C}\right)\end{array}$ & $0.002 \leq \lambda<0.02$ & $0.002 \leq \lambda<0.02$ & $0.002 \leq \lambda<0.02$
\end{tabular}


The first design proposes inserting a new string of casing into the well bore. This method is the simplest way to close off all 33 perforations found in the candidate well. The dimensions of the new string of casing can be found in Table 9. This design will turn the wellbore into a closed system suitable for a geothermal concentric double pipe heat exchanger. In addition, this design methodology allows for the full length of the well to be used, but results in a smaller inside casing diameter. This design will result in a lower optimum mass flow rate caused by the reduction in cross sectional area for fluid flow. The increased casing thickness will create a larger thermal resistor between the working fluid and the formation reducing the heat transfer rate into the working fluid from the formation. The benefit of this design is that the system can utilize the high temperatures found at the bottom of the well. Due to the dimensional constraints created by the new string of casing, only the smallest VIT model will fit within the well bore.

The second proposed design involves placing a cement plug at a depth of $2800 \mathrm{~m}$ which will plug the well above the highest perforation allowing the remaining well bore to be used as a closed system. This design will be relatively inexpensive to implement. It requires a packer to be placed in the well bore above the perforations, cement is then poured on top of the packer and allowed to set. The design results in a shallow well, but with a larger internal diameter than found in Design 1. A higher flow rate will be possible with this design due to the larger cross sectional flow area, but the fluid will be cut off from the higher temperatures found at the bottom of the well. The trade off of higher flow rate but lower temperatures may balance out and produce similar heat flows to design one.

A series of cement squeezes are proposed for Design 3 to close off the perforations. A cement squeeze is a process where cement is forced into voids along the casing wall at a target location. In this case, the cement will be forced out of the well bore and into the formation filling the perforations in the casing and closing off the well. This process allows the well bore to be closed without sacrificing the internal diameter or the total depth of the well. This process is a more expensive option than inserting a 
new string of casing or a simple concrete plug because of the number of perforations found in the candidate well. Although, in a well with few perforations, this process would be a more cost friendly option than re-casing the entire well. It is expected that this design will generate the highest heat flow, while consuming the least pumping power for both the optimized well configuration and the $1.25 \mathrm{MW}$ heat flow configuration. This is due to the maximum depth and cross sectional area being utilized.

\subsection{Results of Simulation and Optimization}

\subsubsection{Results of Re-Cased Full Length Well}

The optimum flow rate found by the model is $0.85 \mathrm{~kg} / \mathrm{s}$ with a net energy flow of $0.20 \mathrm{MW}$, further results can be found in 
Table 10. As can be seen in Figure 11, the working fluid is able to reach a temperature very close to the bottom hole temperature, but the low flow rate also allows a large amount of heat to be lost on the return to surface. The fluid temperature at the bottom of the well is $153^{\circ} \mathrm{C}$, and by the time the fluid reaches the surface it has dropped to a temperature of $133^{\circ} \mathrm{C}$.

At a higher flow rate, the working fluid is unable to reach a value close to the bottom hole temperature, but can maintain its temperature during the return to surface, this behavior can be seen in Figure 11. In order for the re-cased well to reach the objective of a 1.25MW heat flow, a total of 44MW of pumping power is required, as seen in

Table 11. The working fluid reaches a temperature of $144^{\circ} \mathrm{C}$ at the bottom of the well, and drops to a temperature of $138^{\circ} \mathrm{C}$ by the time it has reached the surface.

Table 9: Design 1, Input parameters

Bottom Hole Temperature, $T_{b h}\left({ }^{\circ} \mathrm{C}\right)$

158

TVD (usable), $D(\mathrm{~m})$

5624

Casing Inside Radius, $R_{\mathbf{3}}(\mathrm{m})$

0.053135

Casing Outside Radius, $\mathbf{R}_{\mathbf{4}}(\mathrm{m})$

0.063500

Geothermal Gradient $\left({ }^{\circ} \mathrm{C} / \mathrm{m}\right)$

0.028 
Table 10: Design 1, Optimized Design Results

$\begin{array}{ll}\text { Flow Rate (kg/s) } & 0.85 \\ \text { Heat flow (MW) } & 0.33 \\ \text { Pumping Power (MW) } & 0.13 \\ \text { Net Power (MW) } & 0.20\end{array}$

Table 11: Design 1, Target Heat Flow Results

Flow Rate (kg/s) $\quad 3.04$

Heat flow (MW) 1.25

Pumping Power (MW) 44

Net Power (MW)

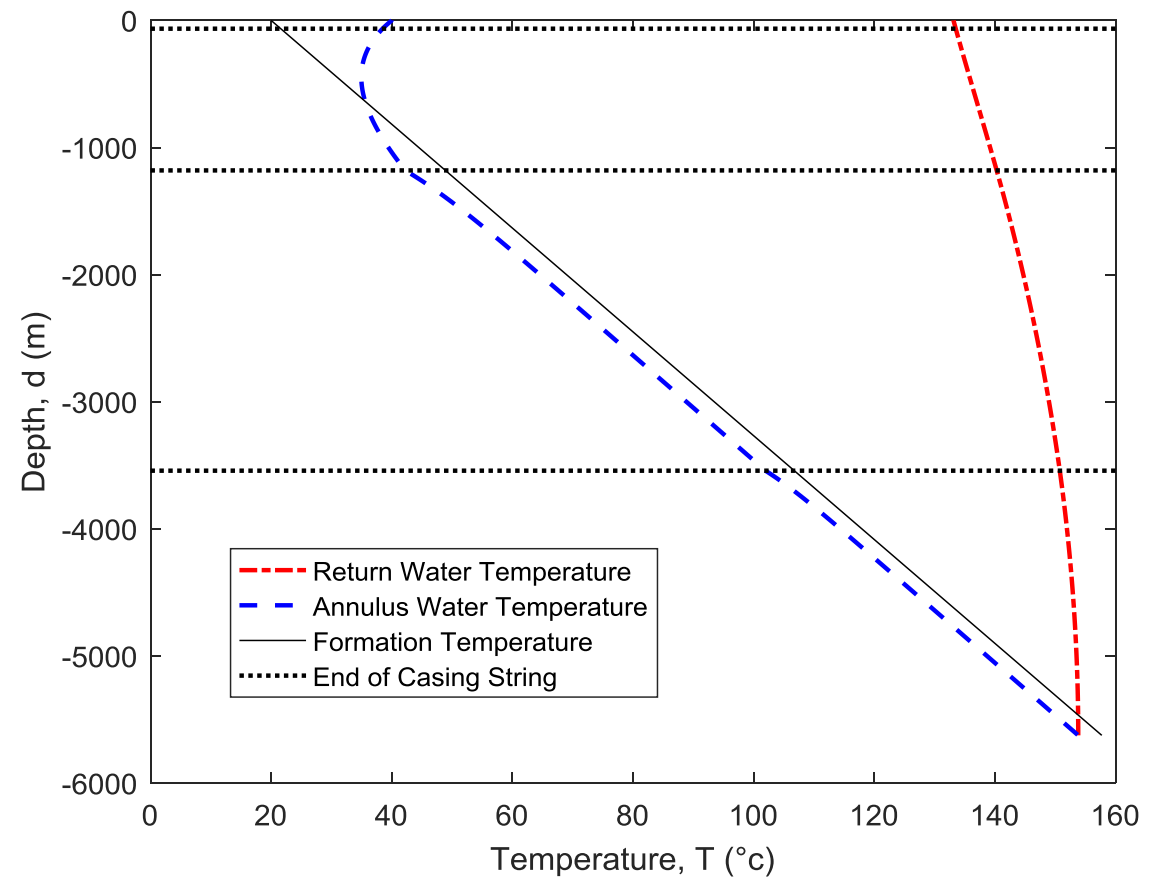

Figure 11: Design 1, Optimized Heat Flow Well Temperature Profile 


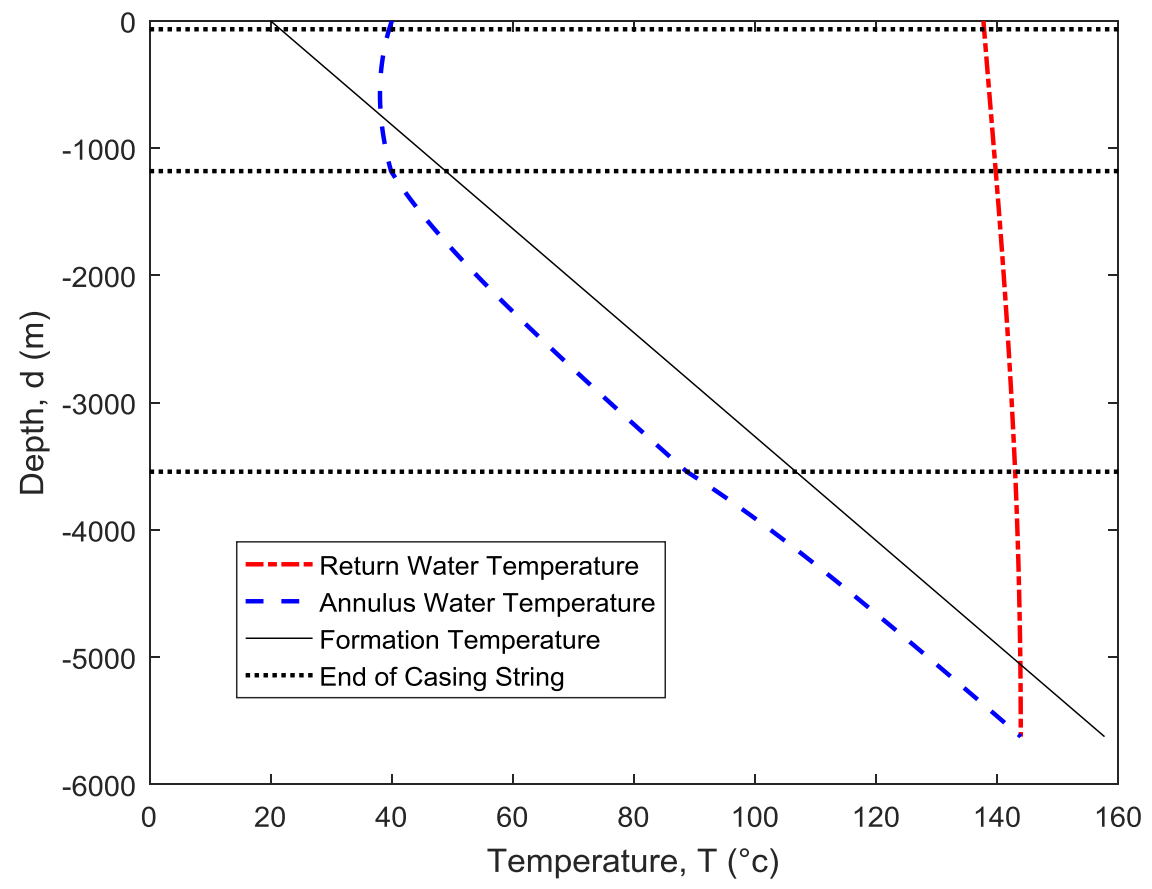

Figure 12: Design 1, Objective heat flow Temperature Profile

\subsubsection{Results of Cement Plug}

With a cement plug placed at a depth of $2800 \mathrm{~m}$, the resulting bottom hole temperature is $78.4^{\circ} \mathrm{C}$. The wells internal radius of $0.072645 \mathrm{~m}$ is able to accommodate all three models of VIT tubing found in Table 8. Because of the low bottom hole temperature, a well design capable of reaching $1.25 \mathrm{MW}$ could not be achieved. As the flow rate is increased, the maximum fluid temperatures achieved decreased this relationship made a $1.25 \mathrm{MW}$ heat flow impossible, this behavior can be seen in Figure 13. 


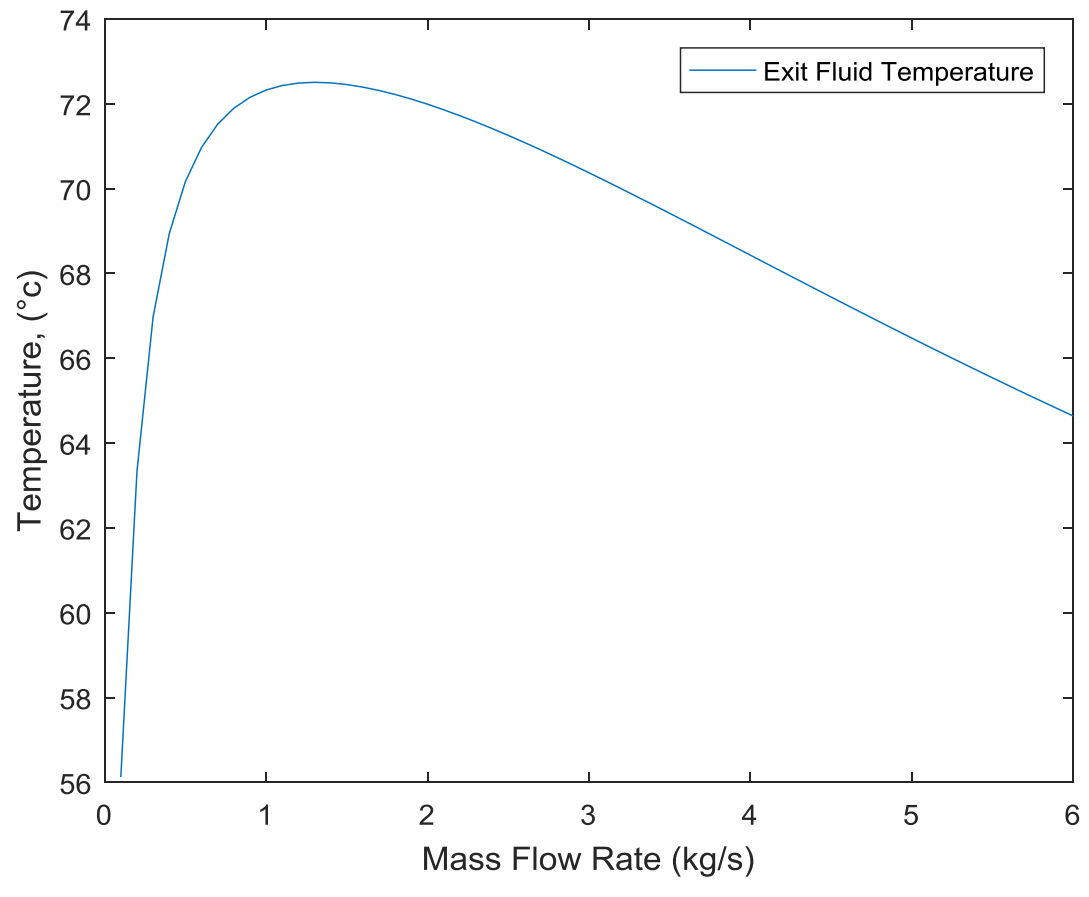

Figure 13: Design 2, Exit Temperature versus Mass Flow Rate

The input parameters for Design 2 are found in Table 12, and the optimum well configuration is found in Table 13. The VIT used is model $4.5 \times 3.5$ with a mass flow rate of $4.61 \mathrm{~kg} / \mathrm{s}$. This configuration was able to produce a $0.45 \mathrm{MW}$ heat flow while consuming $0.08 \mathrm{MW}$ of pumping power. The working fluid is able to reach a temperature of $64^{\circ} \mathrm{C}$, and maintain a temperature of $63^{\circ} \mathrm{C}$ at the surface. With an outlet fluid temperature just below the minimum for binary power generation, this system is not suitable for power generation, but is useful as a source for district heating, or for a geothermal heat pump.

Table 12: Design 2, Input Parameters

Bottom Hole Temperature, $T_{b h}\left({ }^{\circ} \mathrm{C}\right)$

TVD (usable), $D(\mathrm{~m})$

Casing Inside radius, $R_{3}(\mathrm{~m})$

Geothermal Gradient $\left({ }^{\circ} \mathrm{C} / \mathrm{m}\right)$
78.4

2800

0.072645

0.028 


\section{Table 13: Design 2, Optimized Design Results}

$\begin{array}{ll}\text { Optimum VIT Size } & 4.5 \times 3.5 \\ \text { Optimum Flow Rate }(\mathrm{kg} / \mathrm{s}) & 4.61 \\ \text { Heat flow at Optimum Flow Rate (MW) } & 0.45 \\ \text { Pumping Power (MW) } & 0.08 \\ \text { Net Power (MW) } & 0.37 \\ \text { Maximum Fluid Temperature }\left({ }^{\circ} \mathrm{C}\right) & 64 \\ \text { Exit Fluid Temperature }\left({ }^{\circ} \mathrm{C}\right) & 63\end{array}$

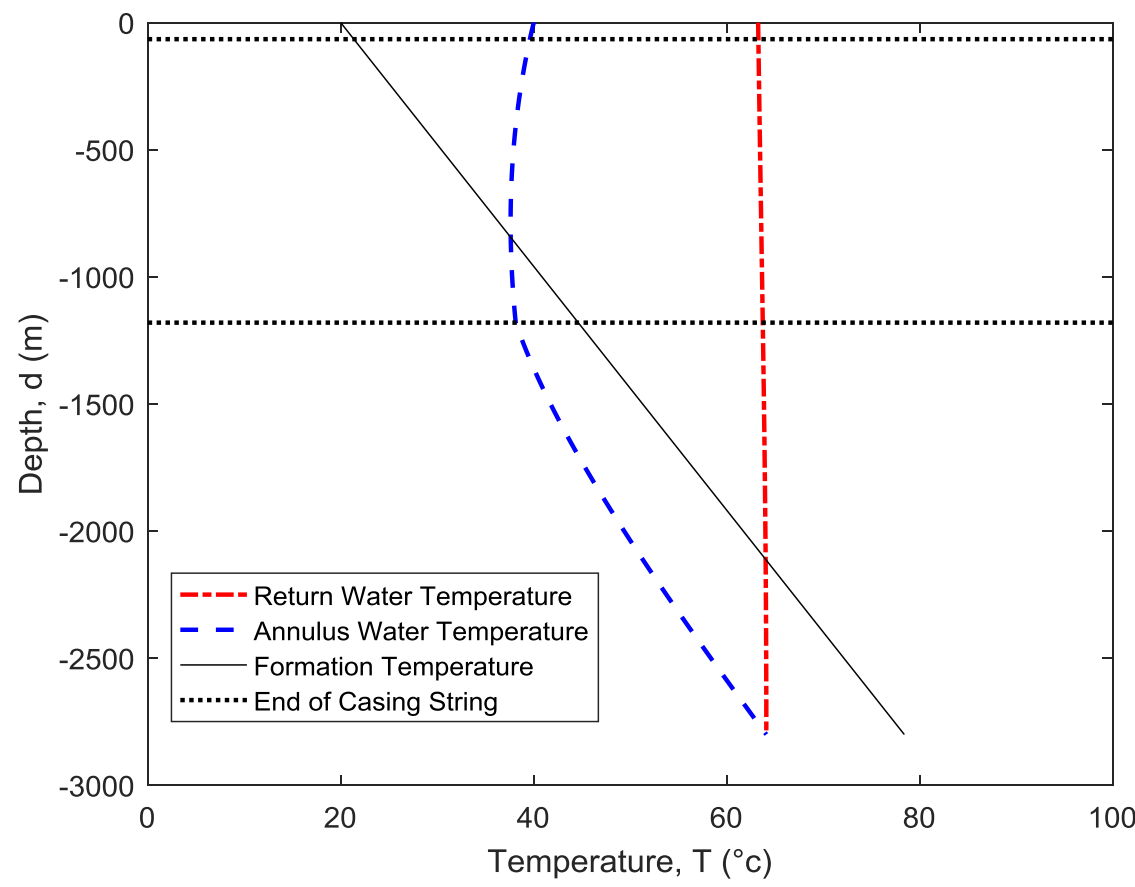

Figure 14: Design 2, Optimized Well Temperature Profile

\subsubsection{Results of Cement Squeeze Well}

The Cement squeezed well design allows for the maximum well depth, and internal diameter to be utilized, the input parameters are found in Table 14. The optimum operating configuration are found in Table 15. The optimum configuration uses a flow rate of $8.19 \mathrm{~kg} / \mathrm{s}$, utilizing the model $4.5 \times 3.5 \mathrm{VIT}$. 
This results in a heat flow of $3.4 \mathrm{MW}$ and a pumping power requirement of $0.96 \mathrm{MW}$. This designs optimum flow rate produces a heat flow much greater than the targeted heat flow.

For each VIT option, the mass flow rate which produced a $1.25 \mathrm{MW}$ heat flow was found, these results are found in Table 16. The most effective option of these three configurations uses the VIT model $4.5 \times 3.5$. The flow rate required is $2.89 \mathrm{~kg} / \mathrm{s}$ which requires a pumping power of $0.043 \mathrm{MW}$.

Table 14: Design 3, input parameters

Bottom Hole Temperature, $T_{b h}\left({ }^{\circ} \mathrm{C}\right)$

TVD (usable), $D(\mathrm{~m})$

Casing Inside radius, $R_{3}(\mathrm{~m})$

Geothermal Gradient, $\left({ }^{\circ} \mathrm{C} / \mathrm{m}\right)$
158

5624

0.072645

0.028

Table 15: Design 3, Optimized design results

VIT Size

Flow Rate (kg/s)

Heat flow (MW)

Pumping Power (MW)

Net Power (MW)
$4.5 \times 3.5$

8.18

3.4

0.96

2.4

Table 16: Design 3, Target heat flow results

\begin{tabular}{|l|lll|}
\hline MODEL & $\mathbf{5 . 5} \mathbf{X} \mathbf{4 . 5}$ & $\mathbf{4 . 5 \times 3 . 5}$ & $\mathbf{3 . 5} \mathbf{2} \mathbf{2 . 3 7}$ \\
\hline FLOW RATE (KG/S) & 2.95 & 2.89 & 2.82 \\
\hline HEAT FLOW (MW) & 1.25 & 1.25 & 1.25 \\
\hline PUMPING POWER (MW) & 4.028 & 0.043 & 4.65 \\
\hline NET POWER (MW) & -2.77 & 1.21 & -3.40 \\
\hline
\end{tabular}




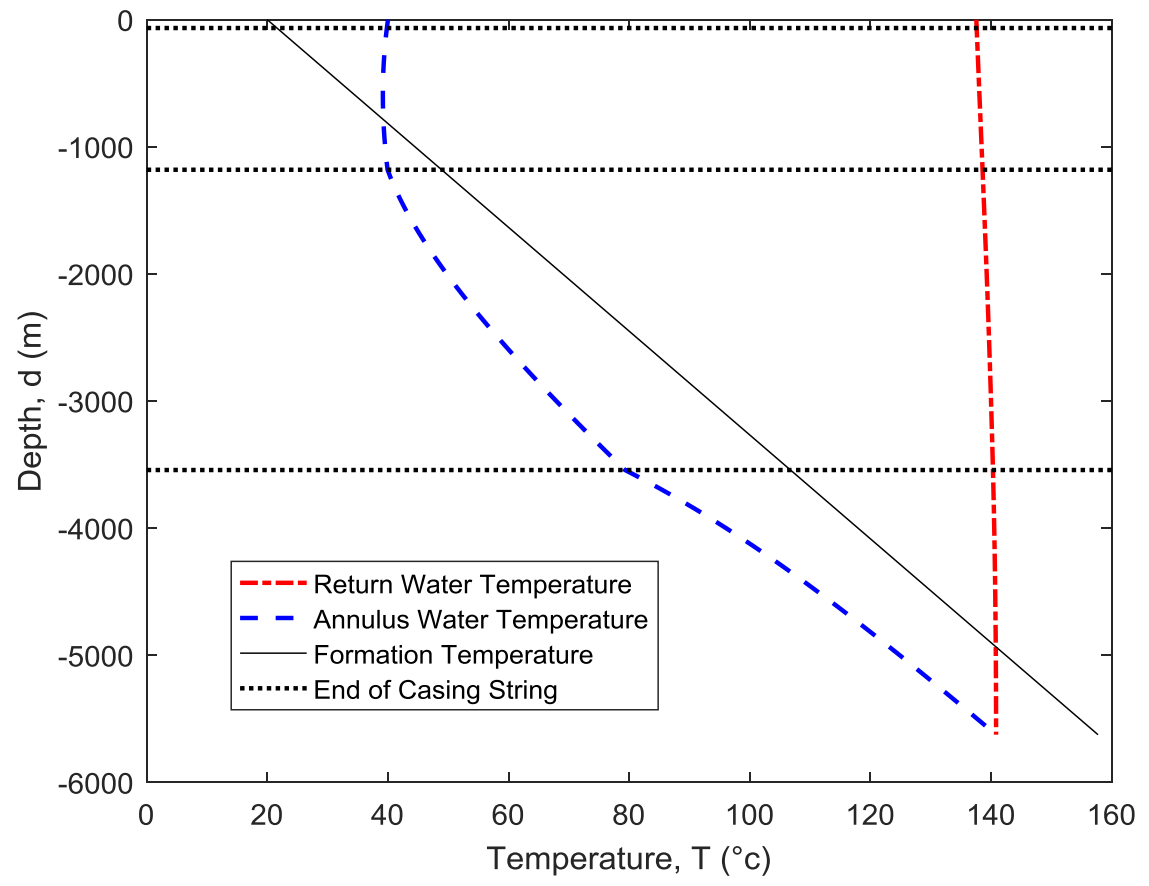

Figure 15: Design 3, Optimized Well Temperature Profile

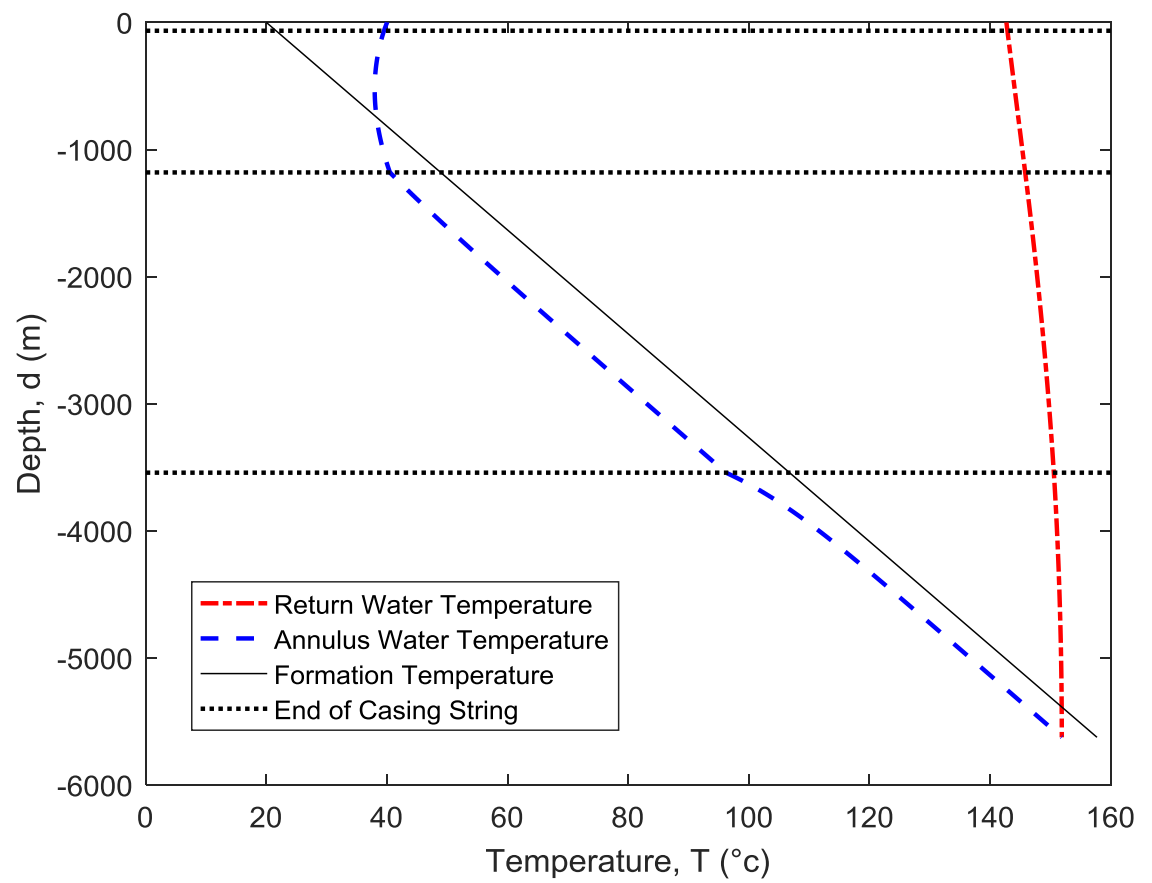

Figure 16: Design 3, Objective Heat Flow Temperature Profile. VIT Model 4.5X3.5 


\subsection{Discussion of Results}

The results of the optimized well configurations are summarized in Table 17, and the results of wells configured to produce a $1.25 \mathrm{MW}$ heat flow are summarized in Table 18 . The cement squeeze well design is capable of producing the most net power for both the optimized system, and for the target 1.25MW heat flow. The downside of this design, is the high cost of squeezing off 33 perforations, an economic study is needed to decide whether the higher energy output justifies the cost of construction, but that is beyond the scope of this report. Design 3 is the only well design capable of producing 1.25MW without having a negative net energy, and at its optimum flow rate can produce a heat flow much greater than the target heat flow.

Table 17: Comparison of Optimized Well Configurations

\begin{tabular}{r|ccc} 
& \multicolumn{1}{c}{ RE-CASED } & \multicolumn{1}{c}{ CEMENT } & \multicolumn{1}{c}{ CEMENT } \\
& WELL & PLUG & 8.19 \\
FLOW RATE (KG/S) & 0.85 & 0.61 & 3.4 \\
HEAT FLOW (MW) & 0.33 & 0.45 & 0.96 \\
PUMPING POWER & 0.13 & 0.08 & \\
(MW) & & & 2.4
\end{tabular}

Table 18: Comparison of 1.25MW Heat Output Configurations

\begin{tabular}{|c|c|c|c|}
\hline & RE-CASED & CEMENT & CEMENT \\
\hline & WELL & PLUG & SQUEEZE \\
\hline FLOW RATE (KG/S) & 3.04 & N/A & 2.89 \\
\hline HEAT FLOW (MW) & 1.25 & N/A & 1.25 \\
\hline $\begin{array}{r}\text { PUMPING POWER } \\
(\mathrm{MW})\end{array}$ & 44 & N/A & 0.043 \\
\hline NET POWER (MW) & -42.75 & N/A & 1.21 \\
\hline
\end{tabular}

The results have demonstrated that there are two trade offs when increasing the flow rate of the working fluid. The first trade off is as the flow rate increases there is a decrease in the maximum temperature achieved by the working fluid at the bottom of the well but less heat loss from the working 
fluid on the return to surface. This trade off is demonstrated when comparing the temperature profiles of the optimum and objective well configurations for Design 1 found in Figure 11 and Figure 12. At the optimum flow rate, the working fluid is able to reach approximately the bottom hole temperature, but is unable to maintain that high temperature for the entire journey to the surface. In the objective flow regime, the fluid is unable to reach the high temperature found at the bottom of the well, but is able to produce an exit temperature closer to the maximum fluid temperature achieved. In both cases, the fluid exits the well at approximately the same temperature, $133^{\circ} \mathrm{C}$ from the optimized well, and $138^{\circ} \mathrm{C}$ from the $1.25 \mathrm{MW}$ well.

The second trade off is between the pumping power required to increase the mass flow rate and to the increased heat flow created by the higher mass flow rate. This relationship can be seen in Figure 17. The heat flow grows in a nearly linear manner with increasing fluid velocities as seen in:

$$
\dot{Q}_{\text {total }}=\dot{m}\left(C_{p_{h}}^{1} T_{h}^{1}-C_{p_{c}}^{1} T_{c}^{1}\right)
$$

Where the total heat flow, $Q_{\text {total, }}$ is proportional to the mass flow rate. This linearly growing heat flow is competing against the pumping power which grows in a quadratic manner. The quadratic growth of the pumping power is caused by the squared velocity found in the pressure head equations:

$$
\begin{aligned}
h_{f_{\text {annulus }}}^{j} & =f_{\text {annulus }}^{j} \frac{\Delta x}{D_{h}} \frac{\left(V_{\text {annulus }}^{j}\right)^{2}}{2 g} \\
h_{f_{\text {tubing }}}^{j} & =f_{\text {tubing }}^{j} \frac{\Delta x}{D} \frac{\left(V_{\text {tubing }}^{j}\right)^{2}}{2 g}
\end{aligned}
$$

The pressure heads are then factored into the pumping power equation creating the quadratic growth.

$$
P_{\text {pump }}=\dot{m}\left(\sum_{j=1}^{n} h_{f_{\text {annulus }}}^{j}+\sum_{j=1}^{n} h_{f_{\text {tubing }}}^{j}\right) g
$$


When examining Figure 17, it becomes evident how the mass flow rate relates to both the heat flow and the pumping power.

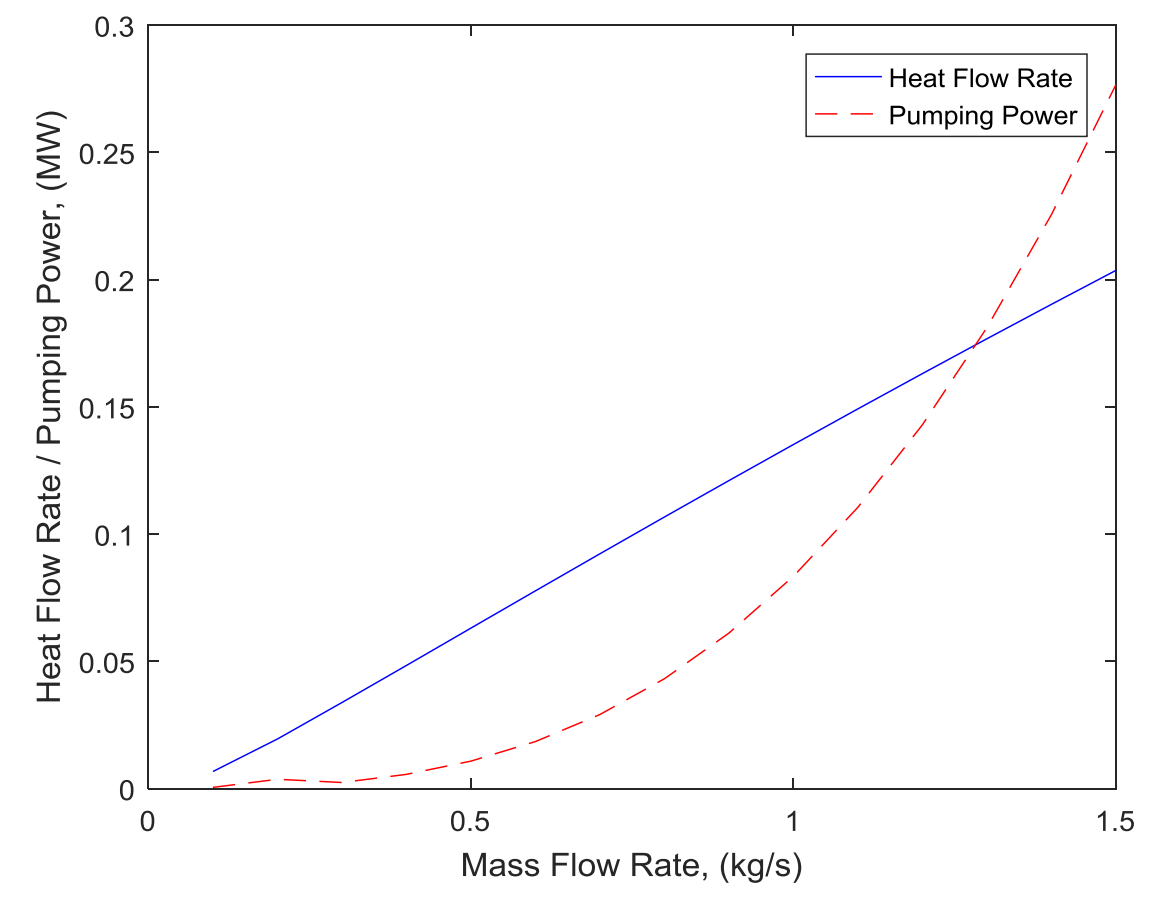

Figure 17: Heat Flow Rate and Pumping Power of Design 2 with respect to the Mass Flow Rate.

It is clear from both the governing equations and the results, that well depth, well diameter, and geothermal gradient have a large effect on the effectiveness of a well for use as a closed geothermal system. A larger diameter well bore allows for slower fluid velocities without affecting the mass flow rate. This creates smaller frictional losses without effecting the heat flow rate, although the slower fluid velocities results in the problem of excessive heat loss on the return to surface. The effectiveness of increasing the well bore diameter can be seen when comparing the optimum well configurations of Design 1 and Design 3. The effectiveness of Design 3 is drastically greater than Design 1, with the only difference being the diameters of the casing, and model of VIT used. 
The depth of the well also plays a part in the frictional losses, although to not as great an extent as the well diameter. The relationship between depth and the friction head loss is linear, reducing the length of the well does not reduce the head loss as effectively as an increased well diameter. In addition, shallower wells are likely to have lower bottom hole temperatures.

When retrofitting oil wells into geothermal systems, ideally the well should have a large inside diameter, and be in a region characterized by a high geothermal gradient. Wells with large numbers of perforations are not recommended as the cost to squeeze off each perforation is most likely an uneconomic choice, and further reduction in the internal diameter caused by a new string of casing has a detrimental effect on the well performance.

Attempting to economically produce a heat flow of $1.25 \mathrm{MW}$ is an ambitious goal with the candidate well used in this study because of the need to close off the 33 perforations. The low geothermal gradient is the main factor preventing this well from producing larger heat flows at shallower depths. If the candidate well were located in a region with a temperature gradient of $0.04^{\circ} \mathrm{C} / \mathrm{m}$ which is closer to the upper end of what is found in Alberta. The bottom hole temperature of the candidate well would be $225^{\circ} \mathrm{C}$, and at a depth of $2800 \mathrm{~m}$ there would be a temperature of $112^{\circ} \mathrm{C}$. The heat flow will almost double with this temperature gradient, but without any additional cost of pumping power. Under these circumstances, producing a $1.25 \mathrm{MW}$ heat flow becomes a much more economical goal.

\subsection{Internal Heat Generation}

The MATLAB model used for these simulations does not take into consideration the heat energy generated by the frictional losses. This was intentionally excluded because the internal heat generated by frictional losses was expected to be negligible. The large pumping powers required to produce the 
targeted 1.25 MW heat flows will possibly cause significant internal heat generation and need to be accounted for in the mathematical model.

The inclusion of internal heat generation caused by frictional losses is achieved by adding the term $Q_{\text {friction }}$ to equation 31:

$$
Q_{\text {friction }}=\dot{m} C_{p} \Delta T
$$

Where,

$$
\Delta T=\frac{\Delta P}{\rho C_{p}}
$$

And,

$$
\Delta P=f \frac{\rho}{2} \frac{V^{2}}{D_{h}} \Delta x
$$

This results in:

$$
Q_{\text {friction }}=\frac{\dot{m} \Delta P}{\rho}
$$

Equation 38 can be included into equation 34

$$
T_{c}^{j}=\frac{u_{c}^{j} A_{c} T_{R}^{j}+\dot{m} C_{p_{c}}^{j-1} T_{c}^{j-1}+u^{j} A_{t} T_{h}^{j}+\frac{\dot{m} \Delta P^{j}}{\rho^{j}}}{u_{c}^{j} A_{c}+\dot{m} C_{p_{c}}^{j}+u^{j} A_{t}}
$$

In order to investigate the effect the internal heat generation term has on the simulation results, Design 1 has been re-simulated to find its operating configuration to produce a $1.25 \mathrm{MW}$ heat flow with frictional heat generation included. Table 19 shows that Internal generation does have a large effect on 
the heat flow of Design 1. The mass flow rate drops by to a value of $1.48 \mathrm{Kg} / \mathrm{s}$, and the pumping power drops to $0.69 \mathrm{MW}$. The effect of including internal heat generation is very large and cannot be considered negligible in this simulation. Figure 18 displays the temperature profile for Design 1 when internal heat generation is included. Due to the narrow internal diameter of the center tubing, a great deal of frictional heat is generated on the fluids return to surface. The hot water reaches a temperature of $151^{\circ} \mathrm{C}$ at the bottom of the well, and continues to increase in temperature reaching an exit temperature of $233^{\circ} \mathrm{C}$.

Table 19: Design 1, Effect of Internal Generation on 1.25MW Heat Flow Regime

\begin{tabular}{r|ccc} 
& $\begin{array}{c}\text { RESULTS INCLUDING } \\
\text { INTERNAL GENERATION }\end{array}$ & $\begin{array}{c}\text { ORIGINAL } \\
\text { RESULTS }\end{array}$ & $\begin{array}{c}\text { PERCENT } \\
\text { CHANGE }\end{array}$ \\
\hline $\begin{array}{r}\text { FLOW RATE } \\
\text { (KG/S) }\end{array}$ & 1.48 & 3.04 & 51 \\
HEAT FLOW & 1.25 & 1.25 & - \\
(MW) & & 44 & 98 \\
PUMPING & 0.69 & -42.75 & 101 \\
POWER (MW) & & &
\end{tabular}

The effect internal generation will have on Design 2, will allow for a 1.25MW heat flow but will require a pumping power close to $1.25 \mathrm{MW}$. The majority of heat will be generated through friction, this is not the intention of these systems and is not an efficient way to convert electricity into heat. 


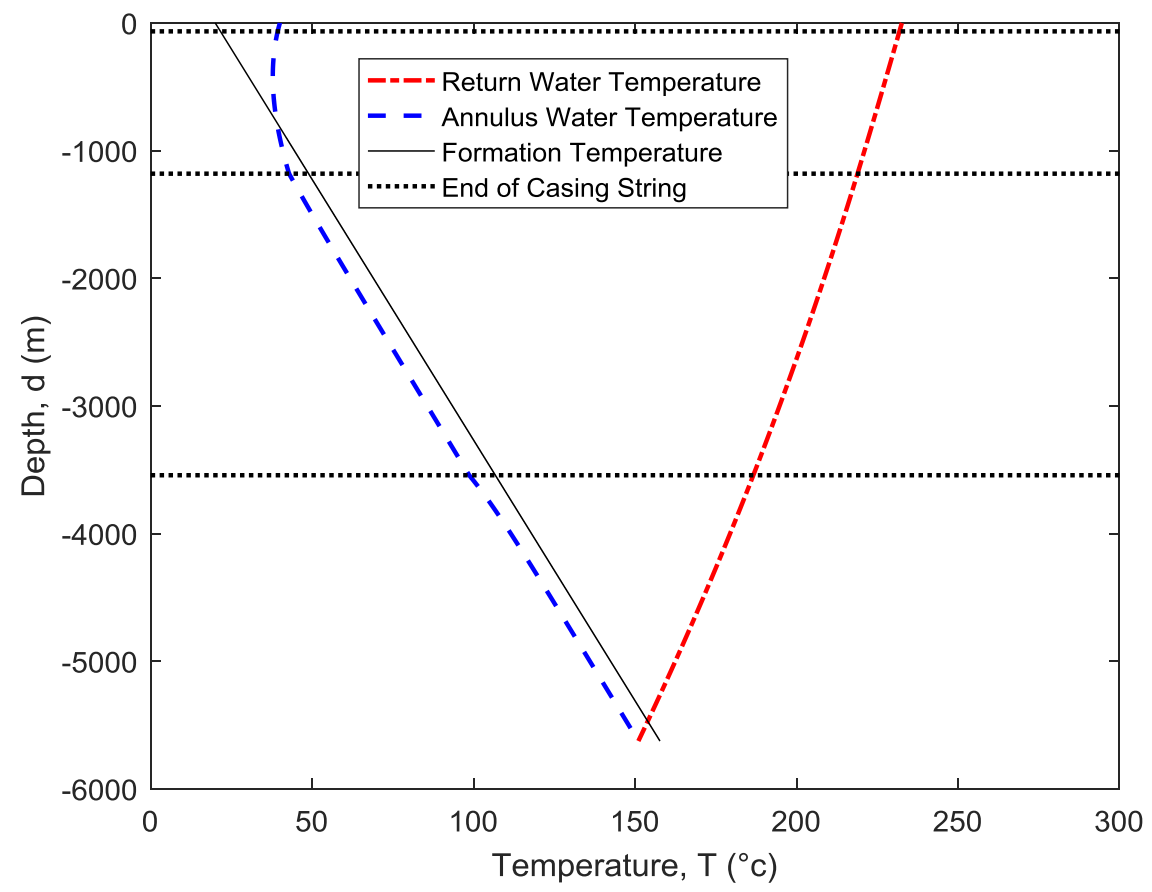

Figure 18: Design 1, Temperature Profile when Internal Heat Generation is Included

Design 3 will have very small effects caused by internal heat generation when creating a heat flow of $1.25 \mathrm{MW}$, this is because of the relatively small pumping powers of $0.043 \mathrm{MW}$. The optimum flow rate designs need re-simulation with the internal heat generation term because the heat flows and pumping powers are of similar scale.

Internal heat generation has an interesting effect on these systems, as a negative net power is now impossible. This is not necessarily true, because of efficiency losses found in the pump system. If the net power is close to zero, including pump efficiency into the equation will in some cases push the net power into the negatives. Additionally, on the basis of cost, if the geothermal system does not produce a large net power, then the system is not worth the cost of construction, much cheaper options exist for converting electricity into heat. 


\section{Chapter 4 Conclusion and Recommendations}

\subsection{Conclusion}

A geothermal system for use in abandoned oil and gas wells in Alberta was requested to be designed. The design needed to accommodate the constraints that no geothermal fluids would be present, formation temperatures would be around $125^{\circ} \mathrm{C}$, and well depths would be greater than $3000 \mathrm{~m}$. After the Initial research phase, a concentric double pipe heat exchanger system was decided to be the best system for the prescribed constraints.

A model for predicting the recovered temperature, as well as the pumping power required was designed through three stages. First a Microsoft Excel spreadsheet was created to predict the heat loss from the hot fluid flowing in the center pipe to the surrounding cold fluid. This was an initial feasibility test, as it was predicted that the heat loss from the hot fluid to the incoming cold fluid would be the greatest challenge for this design. This initial test showed that with the use of VIT, minimal heat loss could be achieved and useful temperatures could be extracted at surface.

Following the Microsoft Excel spreadsheet, a MATLAB program was designed. This program built off the calculations conducted in the Excel spreadsheet, adding in the heat transfer from the casing wall into the cold fluid and the pumping power calculations. The results of this program are in agreement with the initial Microsoft Excel spreadsheet, the main difference being the bulk fluid temperature at the bottom of the well was slightly lower than the assumed temperature in the Excel spreadsheet. This small difference is approximately the same value as the difference in exit fluid temperatures. This MATLAB program assumed that the casing wall temperature would be equal to the formation temperature, which is an inaccurate assumption and was addressed in the third model created.

The second MATLAB program created for the modeling of a concentric double pipe heat exchanger expanded on the heat transfer equations between the formation and the working fluid. The 
casing geometry is now modeled as a thermal resistor between the formation and the working fluid. The outside wall of the casing is assumed to be the same temperature as the formation. This model created some interesting results compared to the previous MATLAB model, a noticeable increase in temperature change is seen at every point a string of casing ends. This change in the heat transfer equations caused a lower temperature achieved at the bottom of the well than seen with the first two models.

Once the model was created, a candidate well for retrofitting as a geothermal well was selected in the Hinton region of Alberta. This well has a bottom hole temperature of $158^{\circ} \mathrm{C}$, and a depth of $5624 \mathrm{~m}$. The well has 33 perforations in the casing which need to be remedied before a concentric double pipe geothermal heat exchanger can be installed. Three designs were proposed to complete this task, each design was tested to find optimal operating conditions, and operating conditions to produce a $1.25 \mathrm{MW}$ heat flow.

The three designs proposed were; 1 ) inserting a new string of casing to close off the well bore, 2) installing a cement plug at a depth of $2800 \mathrm{~m}$ closing off the well from the perforated sections below, and 3) conducting a cement squeeze on all 33 perforations.

The tests conducted showed that, based purely on performance the cement squeeze well is the best option. This is because it allows for the entire depth and internal diameter of the well to be utilized. The downside of this design is that cement squeeze operations are costly and time consuming. An economic study is needed to determine if the superior performance is worth the added cost of installation. Based on the model results for the candidate well, the optimum well configuration produces a heat flow of $3.4 \mathrm{MW}$ while utilizing $0.96 \mathrm{MW}$ of pumping power, this design exceeds the expectations of $1.25 \mathrm{MW}$. 
When analyzing the initial results which neglect internal heat generation, three observations have been made. The first is that there is a tradeoff between the temperature that the fluid is able to reach at the bottom hole versus the heat lost on the return to surface. At higher flow rates, the fluid is unable to achieve temperatures close to the bottom hole temperature, but loses less heat on the return to surface. A lower flow rate corresponds to a higher maximum temperature, but more heat lost on the return to surface.

The second observation is the presence of a tradeoff between the pumping power and the heat flow. The relationship between heat flow and mass flow rate is nearly linear, whereas the relationship between pumping power and velocity is quadratic. This limits the efficient operating conditions to lower mass flow rates where the pumping power has not exceeded the heat flow. Additionally, as well bore diameter increases, larger mass flow rates can be achieved at lower fluid velocities. This helps reduce the required pumping power, while maintaining large mass flow rates for increased heat flows.

The third observation is that well depth plays a role in the effectiveness of the system, there is a linear relationship between depth and the frictional losses, shallower wells are preferred over deep. But more important than depth, areas of higher geothermal gradients allow for shallower wells to be used, while still maintaining the high bottom hole temperatures.

These observations are important for determining what type of wells should be investigated for geothermal retrofitting and the expectations of what these systems can achieve. They are still valid, even though internal heat generation has been neglected in the simulations these observations have been based on. The observations deal with extracting the maximum heat from the formation, an effective geothermal system will not rely on frictional heat generation to produce heat.

Because of the large pumping powers required by these systems, the assumption that internal heat generation caused by friction is negligible was revisited. The necessary terms to include internal heat 
generation in the code was presented and the effect of this additional term was demonstrated on

Design 1. The internal heat generation showed to play a very large role in the heat flow of Design 1. It is concluded that neglecting internal heat generation is not acceptable for the higher mass flow rates of the well configurations producing $1.25 \mathrm{MW}$ heat flows. The initial simulation of the re-cased well design when producing $1.25 \mathrm{MW}$ requires a larger pumping power (44.11MW), the required power for this system is too large to neglect the internal heat generation. When simulated with internal heat generation, the pumping power drops to $0.69 \mathrm{MW}$. This is a vastly different result than initially simulated, it can be concluded that internal heat generation plays a large role in these systems. When conducting future simulations, internal heat generation should be included.

\subsection{Recommendations for Future Studies}

The reality of these geothermal systems is that they are transient in nature. The model presented in this report only predicts the initial heat flows, and does not account for cooling of the formation. Adapting the model to accommodate for the transient nature of the system should be the priority for future work. In order to accurately predict the cooling of rock formations surrounding the well, the thermal properties of each formation are needed. The program will predict the average heat flow over a designated time step, and the long-term performance of the system will be predicted.

The required heat flow for a municipality is not constant and changes with the season. In the summer, very little heat, if any at all, will be required for district heating. In the winter, there will be a large demand. Future studies should be modeled to account for seasonal changes in demand, in order to predict the system's ability to meet these fluctuations and how these fluctuations effect the longevity of the formations heat. Additionally, the studies should investigate the ability of the formation to re-heat over summer periods where there is little demand from the system. To what extent can the formation re-heat, and is it possible to aid in the re-heating of the system. 


\section{Appendix 1: MATLAB Code}

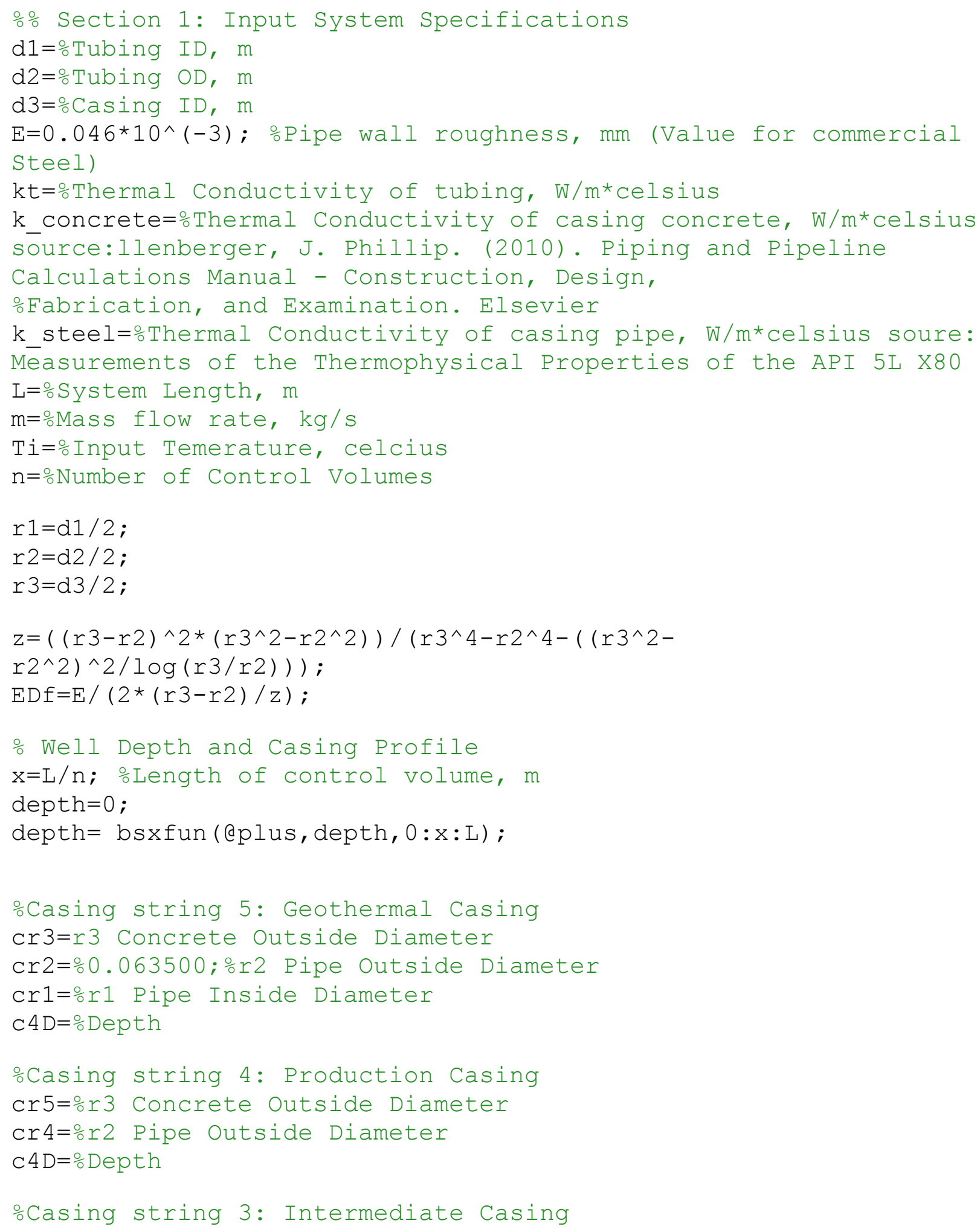




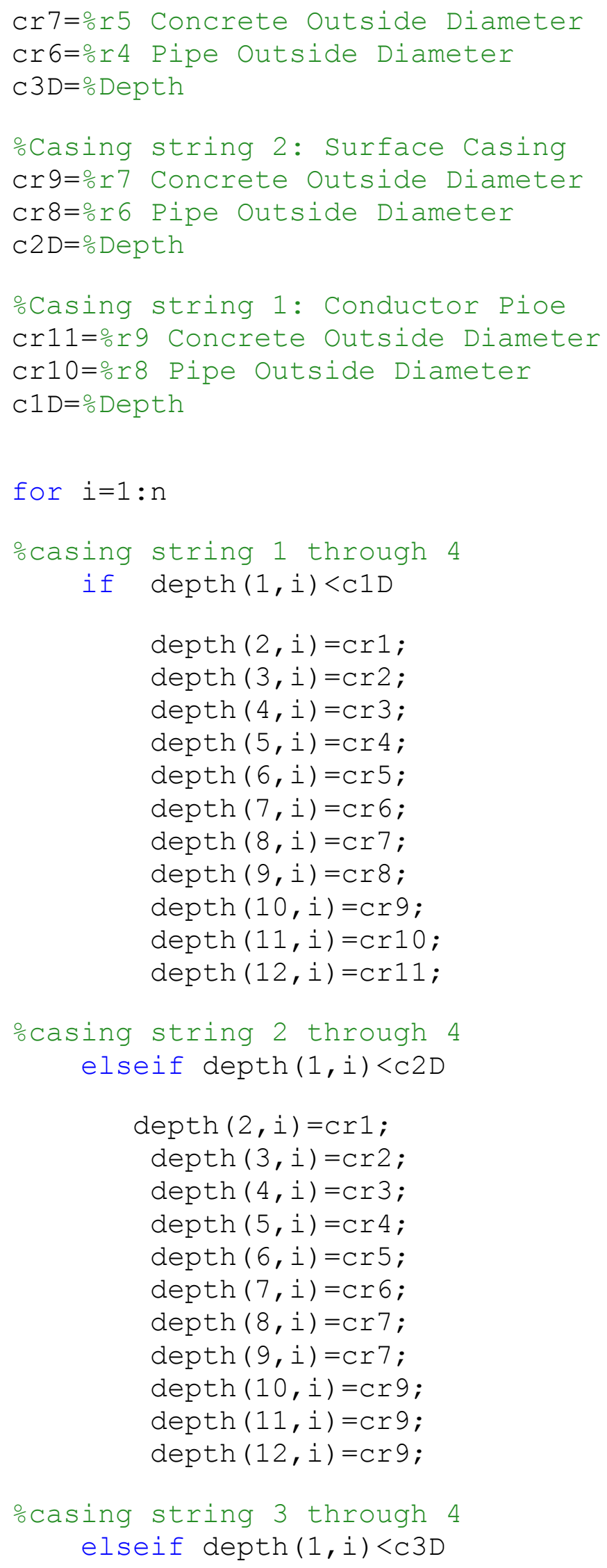




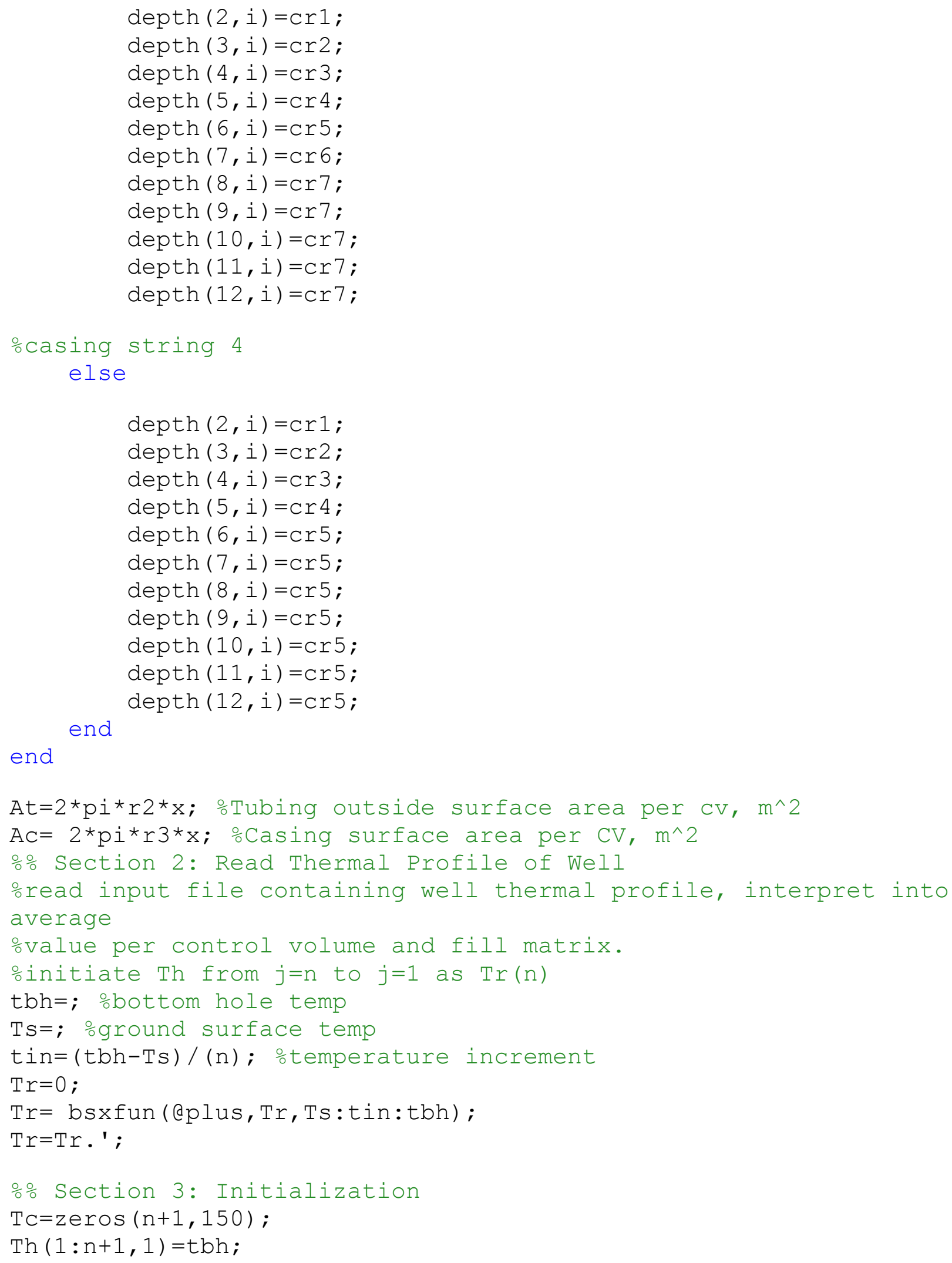


f_c $=$ zeros $(n+1,1)$; ofrictional factor tables

$\mathrm{f}_{-}^{-} \mathrm{h}=\mathrm{f} \_\mathrm{C}$;

h_c $=$ zeros $(n, 1)$; oheat transfer coefficient tables

h_h $(1: \mathrm{n}, 1)=3257.44$;

cp_c $=$ zeros $(n+1,1)$;

$\mathrm{cp}$ h $=\operatorname{zeros}(\mathrm{n}, 1)$;

den $c(1,1)=1.233 * 10^{\wedge}(-9) * 40 \wedge 4+8.476 * 10^{\wedge}(-6) * 40^{\wedge} 3-0.00493 * 40^{\wedge} 2$

$-0.01658 * 40+1000$;

응 Section 4: Control Volume Analysis

o iterate until convergance, value $i$ will be iteration number

o divide problem into $n$ control volumes, $j$ is the control volume number

o one iteration will walk down in a for loop from $j=1$ too $j=n$ calculating the Tc

o then a second for loop will walk up from $j=n$ to $j=1$

calculating Th

$i=0$;

$\mathrm{e}=0$;

while e $<5$

$i=i+1$;

$\mathrm{TC}(1, \mathrm{i})=\mathrm{Ti}$;

for $j=2:(n+1)$; ocalculation of annulus temperatures

$\mathrm{mu} \_\mathrm{C}=1.028 * 10^{\wedge}(-11) * \mathrm{Tc}(j-1, i)^{\wedge} 4-4.255 * 10^{\wedge}(-9) * \mathrm{Tc}(j-$

$1, i)^{\wedge} 3+6 . \overline{5} 54 * 10^{\wedge}(-7) \star \mathrm{TC}(j-1, i)^{\wedge} 2-4.781 * 10^{\wedge}(-5) \star \mathrm{TC}(j-1, i)+$

0.001749 ;

$\operatorname{Re} c=\left(m^{\star}(\mathrm{d} 3-\mathrm{d} 2)\right) /\left(\mathrm{pi} *\left(r 3^{\wedge} 2-\mathrm{r} 2^{\wedge} 2\right) \star m u c\right) ;$

$\mathrm{CP}^{-} \mathrm{C}(j)=9.115 * 10^{\wedge}(-7) * \mathrm{TC}(j-1, i)^{\wedge} 4-\overline{0} .0003004 * \mathrm{TC}(j-$

$1, i)^{\wedge} 3+0 . \overline{0} 4379 * \mathrm{TC}(j-1, i)^{\wedge} 2-2.248 * \mathrm{TC}(j-1, i)+4214 ;$

$\mathrm{k} \_\mathrm{C}=1.426 * 10^{\wedge}(-10) * \mathrm{TC}(j-1, i) \wedge 4-2.698 * 10^{\wedge}(-8) * \mathrm{TC}(j-$

$1, i)^{\wedge} 3-7.684 * 10^{\wedge}(-6) * \mathrm{TC}(j-1, i) \wedge 2+0.002088 * \mathrm{TC}(j-1, i)+0.5603$;

pr_c $=m u_{-}{ }^{*} \mathrm{CP} \mathrm{C}_{-} \mathrm{c}(j) / \mathrm{k} \mathrm{C}_{\mathrm{C}}$;

den_c $(j)=1.2 \overline{3} 3 * 10^{\wedge}(\overline{-9}) * \mathrm{Tc}(j-1) \wedge 4+8.476 * 10^{\wedge}(-6) * \mathrm{TC}(j-$

$1)^{\wedge} 3-0.00 \overline{4} 93 * \operatorname{TC}(j-1)^{\wedge} 2-0.01658 * \operatorname{Tc}(j-1)+1000$; odensity of cold water

oSolving for the frictional factor 


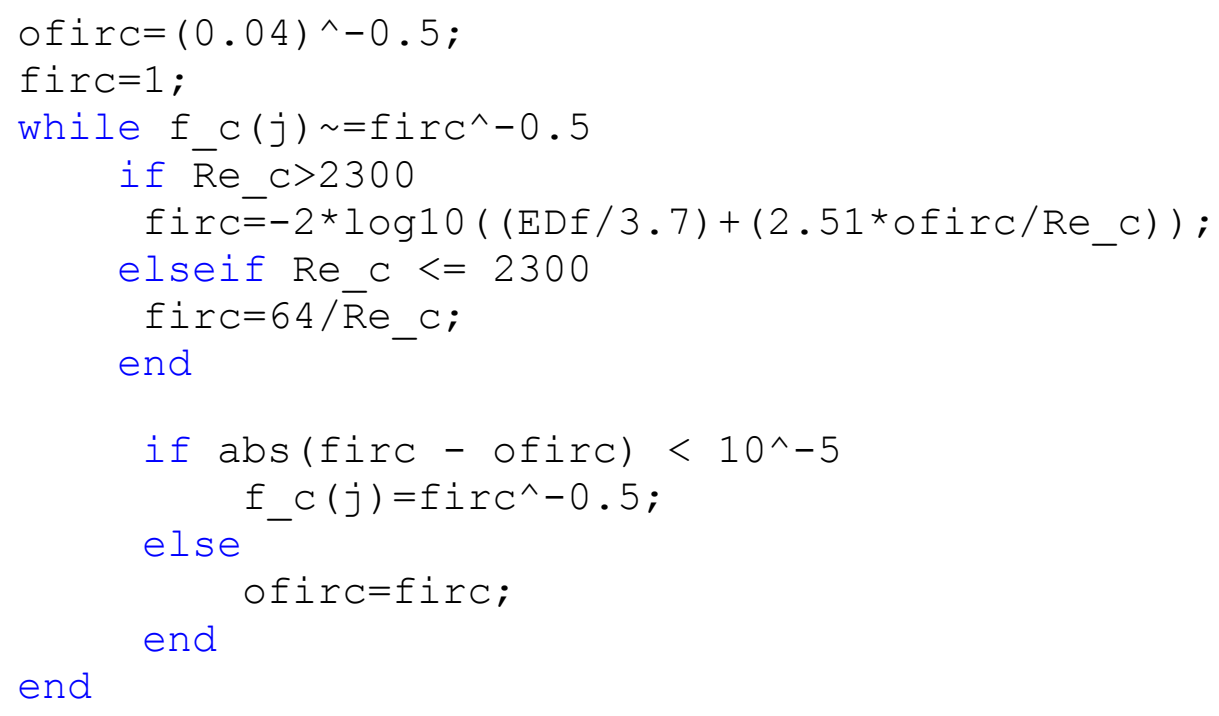

oSolve for Nusselt Number using dittus boelter, and oGnielski modification 


$$
\left.\left.+\left(1 /\left(A^{*}{ }^{*}{ }_{-} C(j-1)\right)\right)\right)\right)^{\wedge}-1 ;
$$

$\mathrm{Tc}(j, i)=\left(\left(u A_{c} * \operatorname{Tr}(j-1)\right)+\left(m^{*} \mathrm{CP}_{-} \mathrm{c}(j) * \mathrm{Tc}(j-1, i)\right)+(u A t * \operatorname{Th}(j-\right.$ $1, i))) /\left((u A c)+\left(m^{\star} c p_{-} c(j)\right)+(u A t)\right) ; \%$

opull out the friction heat

end

fric_c $(j)=\left(m^{*} p_{-} c(j) /\right.$ den_c $\left.(j)\right)$;

$\operatorname{Th}(\mathrm{n}+1, \mathrm{i}+1)=\mathrm{TC}(\mathrm{n}+1, \mathrm{i})$;

for $j=n:-1: 1$ ocalculation of tubing temperatures

mu_h $=1.028 * 10^{\wedge}(-11) * \operatorname{Th}(j+1, i)^{\wedge} 4-4.255 * 10^{\wedge}(-$

$9) * \operatorname{Th}(j+1, \bar{i}) \wedge 3+6.554 * 10^{\wedge}(-7) * \operatorname{Th}(j+1, i) \wedge 2-4.781 * 10^{\wedge}(-$

$5) * \operatorname{Th}(j+1, i)+0.001749$;

$R e \_h=(m * d 1) /\left(p i *\left(r 1^{\wedge} 2\right) * m u \_h\right)$;

$\mathrm{cp}^{-} \mathrm{h}(j)=9.115 * 10^{\wedge}(-7) * \mathrm{Th}(\bar{j}+1, i)^{\wedge} 4-$

$0.0003004 * \overline{T h}(j+1, i) \wedge 3+0.04379 * \operatorname{Th}(j+1, i) \wedge 2-2.248 * \operatorname{Th}(j+1, i)+$ 4214 ;

$\mathrm{k} \_\mathrm{h}=1.426 * 10^{\wedge}(-10) * \mathrm{Th}(j+1, i)^{\wedge} 4-2.698 * 10^{\wedge}(-$

$8) * \operatorname{Th}(j+1, i) \wedge 3-7.684 * 10^{\wedge}(-6) * \operatorname{Th}(j+1, i) \wedge 2+0.002088 * \operatorname{Th}(j+1, i)+$ 0.5603 ;

pr_h $=$ mu_h* cp_h $(j) / \mathrm{k}_{-} \mathrm{h}$;

den $h(j)=1.2 \overline{3} 3 * 10^{\wedge}(\overline{-9}) * \operatorname{Th}(j+1)^{\wedge} 4+8.476 * 10^{\wedge}(-$

$6) * \operatorname{Th}(j+1)^{\wedge} \overline{3}-0.00493 * \operatorname{Th}(j+1)^{\wedge} 2-0.01658 * \operatorname{Th}(j+1)+1000$;

odensity of hot water

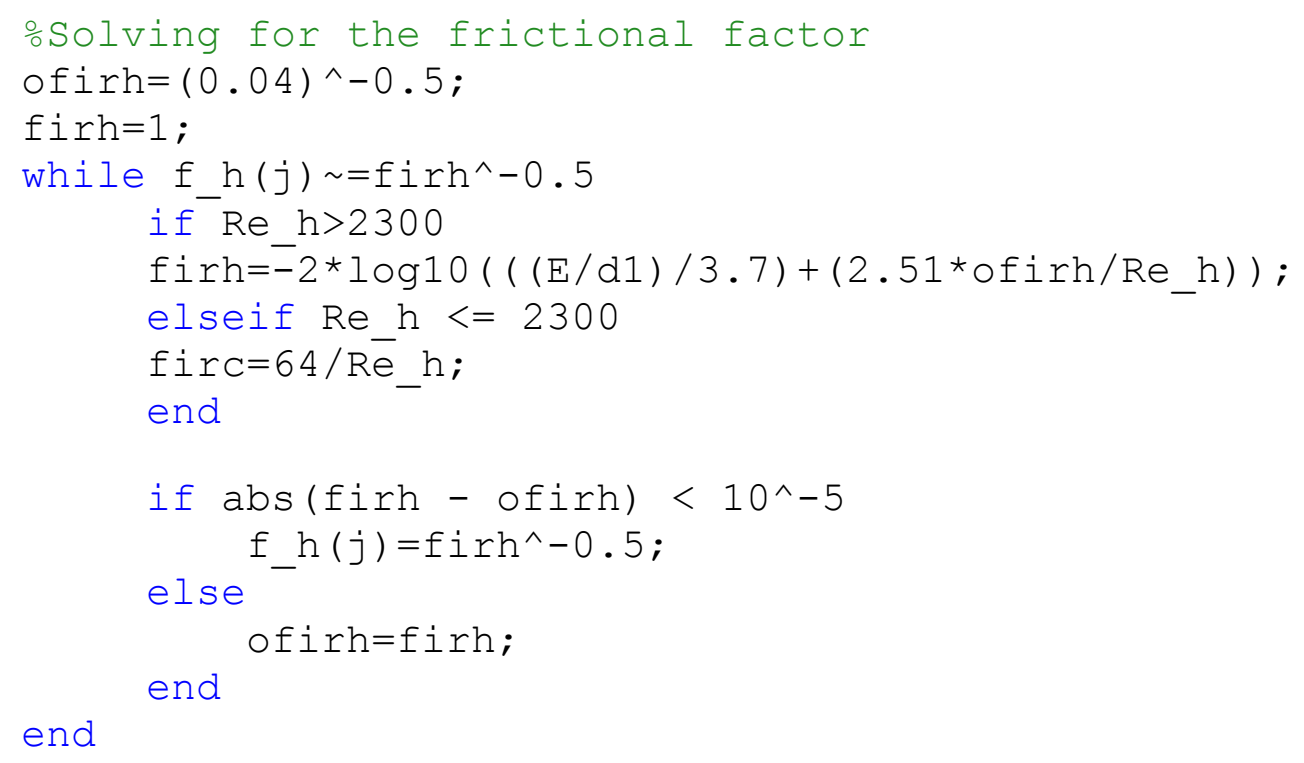




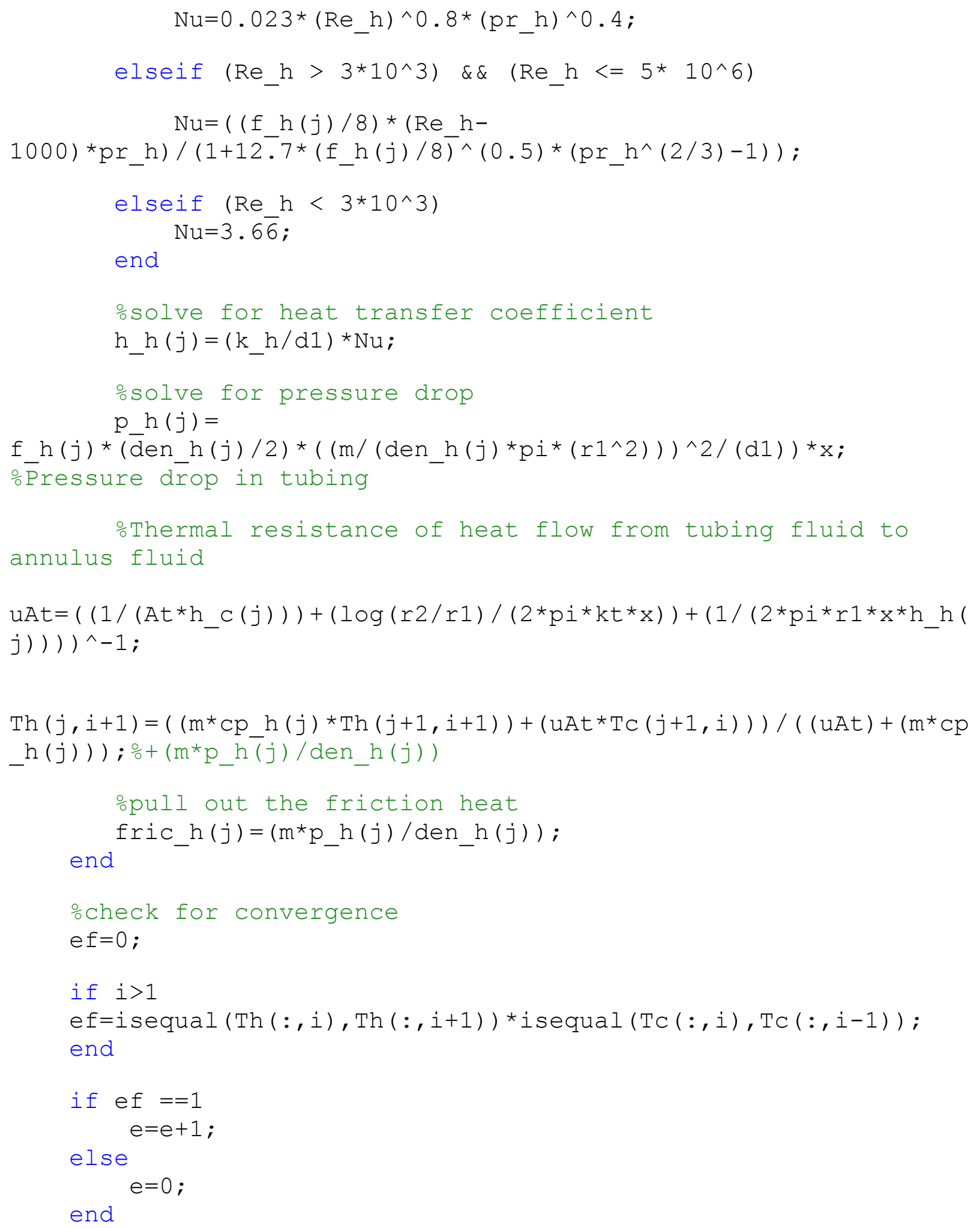




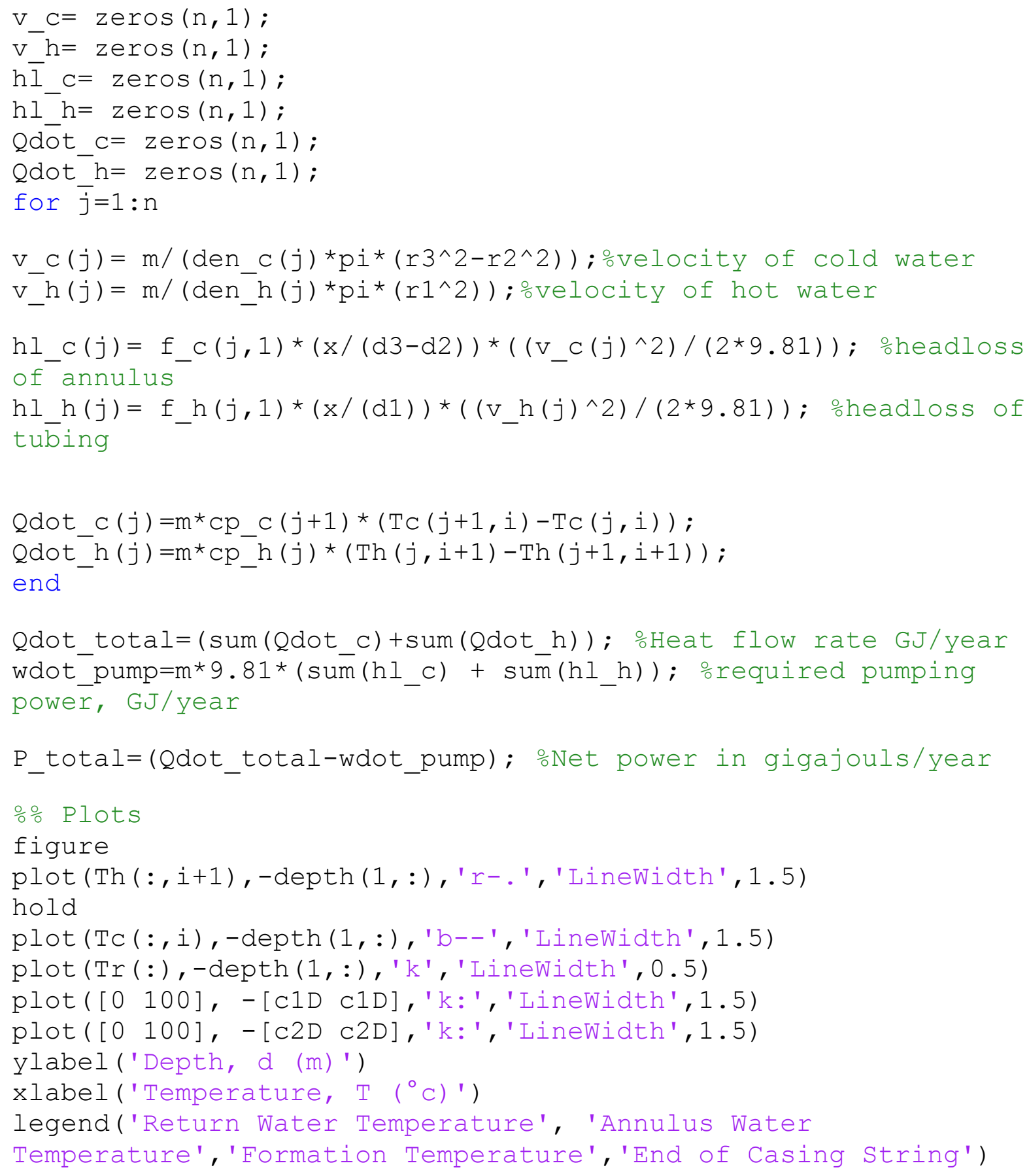




\section{References}

[1] Alberta Government, "Carbon levy and rebates," 2016. [Online]. Available:

http://www.alberta.ca/climate-carbon-pricing.aspx. [Accessed 412 2016].

[2] Government of Alberta, "Phasing out coal pollution," 2016. [Online]. Available:

http://www.alberta.ca/climate-coal-electricity.aspx. [Accessed 412 2016].

[3] Alberta Energy Regulator, "How are Wells Suspended," 2016. [Online]. Available:

https://www.aer.ca/abandonment-and-reclamation/how-are-wells-suspended. [Accessed 4 12 2016].

[4] W. E. Glassley, Geothermal Energy - Renewable Energy and the Environment, Second Edition, Boca Raton, FL: CRC Press , 2014.

[5] M. A. Grant and P. F. Bixley, Geothermal Reservoir Engineering, 2nd Edition, Elsevier, 2011.

[6] J. Templeton, . S. Ghoreishi-Madiseh, F. Hassani and M. Al-Khawaja, "Abandoned petroleum wells as sustainable sources of geothermal energy," Energy, vol. 70, no. 1, p. 366373, 2014.

[7] ASHRAE, "Chapter 34: Geothermal Energy," in ASHRAE Handbook - HVAC Applications, Atlanta, GA, ASHRAE, 2015. 
[8] "10.5 Enhanced Geothermal Systems," in Future Energy - Opportunities and Challenges, Research Triangle Park, NC, ISA, 2013.

[9] M. Kharseh, M. Al-Khawaja and F. Hassani, "Utilization of oil wells for electricity generation: Performance and Economics," Energy, no. 90, pp. 910-916, 2015.

[10] C. Steins, A. Bloomer and S. J. Zarrouk, "Improving the performance of the down-hole heat exchanger at the Alpine Motel, Rotorua, New Zealand," Geothermics, no. 44, pp. 1-12, 2012

[11] D. H. Freeston and H. Pan, "The application and design of downhole heat exchanger," Geothermics, vol. 14, no. 2-3, pp. 343-351, 1985.

[12] Y. Noorollahi, S. M. Bina and H. Yousef, "Simulation of Power Production from Dry Geothermal Well Using Down-hole Heat Exchanger in Sabalan Field, Northwest Iran," Natural Resources Research, vol. 25, no. 2, pp. 227-239, June 2016.

[13] Y. Noorollahi, M. Pourarshad, S. Jalilinasrabady and H. Yousefi, "Numerical simulation of power production from abandoned oil wells in Ahwaz oil field in southern Iran," Geothermics, vol. 55, pp. 16-23, 2015.

N. M. Wight and N. S. Bennett, "Geothermal energy from abandoned oil and gas wells using water in combination with a closed wellbore," Applied Thermal Engineering, vol. 89, pp. 908-915, 2015. 
[15] X. Bu, W. Ma and H. Li, "Geothermal energy production utilizing abandoned oil and gas wells," Renewable Energy, vol. 41, pp. 80-85, 2012.

[16] A. P. Davis and E. E. Michaelides, "Geothermal power production from abandoned oil wells," Energy, vol. 34, no. 7, pp. 866-872, 2009.

[17] T. Kujawa, W. Nowak and A. A. Stachel, "Analysis of the exploitation of existing deep production wells for acquiring geothermal energy," Journal of Engineering Physics and Thermophysics, vol. 78, no. 1, pp. 127-135, 2005.

[18] S. Gow, Roughnecks, rock bits and rigs: the evolution of oil well drilling technology in Alberta, 1883-1970, Calgary: University of Calgary Press, 2005.

[19] Alberta Energy Regulator , "ST 37: List of Wells in Alberta Monthly Updates," Alberta Energy Regulator, Calgary, 2016.

[20] H. L. Lam and F. W. Jones, "Geothermal gradients of Alberta in Western Canada," Geothermics, vol. 13, no. 3, pp. 181-192, 1984.

[21] J. Majorowicz and S. E. Grasby, "Heat flow, depth-temperature variations and stored thermal energy for enhanced geothermal systems in Canada," Journal of Geophysics and Engineering, vol. 7, no. 3, p. 232-241, 2010.

[22] N. J. Hyne, Nontechnical Guide to Petroleum Geology, Exploration, Drilling, and Production (2nd Edition), Tulsa, OK: Penwell, 2001. 
[23] Alberta Energy Regulator, "Directive 008," Alberta Energy Regulator, Calgary, ALTA, 2013.

[24] The Energy Resources Conservation Board, "Directive 010," Alberta Energy Regulator, Calgary, ALTA, 2016.

[25] Andmir Group, "Vacuum Insulated Tubing," 2015. [Online]. Available:

http://www.andmir.com/vacuum-insulated-tubing. [Accessed 9 2016].

[26] Y. A. Cengel and A. J. Ghajar, "Appendix I," in Heat and Mass Transfer: Fundamentals and Applications, Fourth Edition, New York, McGraw Hill, 2011, pp. 865-891.

[27] Y. A. Cengel and A. J. Ghajar, "Chapter 8: Internal Forced Convection," in Heat and Mass Transfer: Fundamentals and Applications, Fourth Edition, New York, McGraw Hill, 2011, pp. 465-518.

[28] F. M. White, "Chapter 6: Viscous Flow in Ducts," in Fluid Mechanics, Seventh Edition , New York, McGraw Hill, 2011, pp. 347-454.

[29] Clear Directional Drilling Solutions, "Hole Size vs. Casing Size," 2016. [Online]. Available: http://cleardirectional.com/. [Accessed 12 2016]. 
